\title{
Correlation of Morphology and Crystal Structure of Metal Powders Produced by Electrolysis Processes
}

\author{
Nebojša D. Nikolić ${ }^{1, * \mathbb{C}}$, Vesna M. Maksimović ${ }^{2}$ and Ljiljana Avramović ${ }^{3}$ \\ 1 Department of Electrochemistry, Institute of Chemistry, Technology and Metallurgy, University of Belgrade, \\ Njegoševa 12, 11000 Belgrade, Serbia \\ 2 Vinča Institute of Nuclear Science, University of Belgrade, 11000 Belgrade, Serbia; vesnam@vin.bg.ac.rs \\ 3 Mining and Metallurgy Institute, Center for Technologies Development in Metallurgy, Zeleni Bulevar 35, \\ 19210 Bor, Serbia; ljiljana.avramovic@irmbor.co.rs \\ * Correspondence: nnikolic@ihtm.bg.ac.rs; Tel.: +381-11-337-0390
}

Citation: Nikolić, N.D.; Maksimović, V.M.; Avramović, L. Correlation of Morphology and Crystal Structure of Metal Powders Produced by Electrolysis Processes. Metals 2021, 11, 859. https://doi.org/10.3390/ met11060859

Academic Editor: Javier S. Blázquez Gámez

Received: 13 April 2021

Accepted: 18 May 2021

Published: 24 May 2021

Publisher's Note: MDPI stays neutral with regard to jurisdictional claims in published maps and institutional affiliations.

Copyright: (c) 2021 by the authors. Licensee MDPI, Basel, Switzerland. This article is an open access article distributed under the terms and conditions of the Creative Commons Attribution (CC BY) license (https:// creativecommons.org/licenses/by/ $4.0 /)$.

\begin{abstract}
In this review paper, morphologies of metal powders produced by the constant (potentiostatic and galvanostatic) regimes of electrolysis from aqueous electrolytes are correlated with their crystal structure at the semiquantitative level. The main parameters affecting the shape of powder particles are the exchange current density (rate of electrochemical process) and overpotential for hydrogen evolution reaction. Depending on them, various shapes of dendrites (the needles, the two-dimensional (2D) fern-like, and the three-dimensional (3D) pine-like dendrites), and the particles formed under vigorous hydrogen evolution (cauliflower-like and spongy-like particles) are produced by these regimes of electrolysis. By decreasing the exchange current density value, the crystal structure of the powder particles is changed from the strong (111) preferred orientation obtained for the needle-like (silver) and the 2D (lead) dendrites to the randomly orientated crystallites in particles with the spherical morphology (the 3D dendrites and the cauliflower-like and the spongylike particles). The formation of metal powders by molten salt electrolysis and by electrolysis in deep eutectic solvents (DESs) and the crystallographic aspects of dendritic growth are also mentioned in this review.
\end{abstract}

Keywords: electrolysis; morphology of particles; the crystal structure; dendrite; hydrogen evolution

\section{Introduction}

Powder metallurgy (PM) is a branch of science including production, characterization, and conversion of metal powders into useful engineering components [1]. The first step in the overall PM is the production of metal powders. Although there is no unique classification of methods for powder production, all methods can be situated into one of the four groups: solid-state reduction, atomization, electrolysis, and chemical processes [2]. Some of the available submethods also include ultrasonic spray pyrolysis [3], solvothermal synthesis [4], cementation [5], pyrolysis [6], hydrometallurgy [7], melt spinning, rotating electrode process (REP), and mechanical processes [8,9]. Metal powders are characterized by their morphology and size of the particles. The shape and size of particles strongly depend on the method used for their preparation [1,10].

Electrolysis is an often-used method for the synthesis of metal powders [10]. This method achieves certain advantages over the other production methods, and the obtained conveniences can be summarized as follows: low equipment and product costs, one-step process, environmentally friendly process, and high purity of obtained products [11].

Metal powders can be obtained by electrolysis from aqueous electrolytes, melt, and deep eutectic solvents (DESs) applying both constant (galvanostatic and potentiostatic) and periodically changing (pulsating current (PC), reversing current (RC), and pulsating overpotential (PO)) regimes of electrolysis $[1,10,12,13]$. There is a strong correlation between the parameters and regime of electrolysis and the shape of powder particles as the final 
product of the electrolysis process. The main shapes of powder particles obtained by electrolysis are as follows: dendrites of various shape, spongy, needles, cauliflower, and fibrous [10]. The shape of particles depends on the kind and composition of the electrolyte, the temperature of electrolysis, the kind of cathode, electrolyte stirring, the addition of additives in an electrolyte, and the nature of metals [10].

The main classification of metals is done according to the exchange current density $\left(j_{0}\right)$, melting point $\left(T_{\mathrm{m}}\right)$, and overpotential for hydrogen evolution reaction [14,15]. Following these parameters, metals are classified into one of the three groups:

(a) Normal metals: metals such as $\mathrm{Pb}, \mathrm{Cd}, \mathrm{Ag}$ (basic electrolytes), Sn, and $\mathrm{Zn}$. These metals are characterized by high $j_{0}$ values $\left(j_{0}>1 \mathrm{~A} \mathrm{dm}^{-2}\right)$, low $T_{\mathrm{m}}$, and high overpotentials for hydrogen evolution reaction.

(b) Intermediate metals: metals such as $\mathrm{Cu}, \mathrm{Ag}$ (ammonium electrolyte), and $\mathrm{Au}$. These metals are characterized by medium $j_{0}$ values $\left(10^{-2}<j_{0}<1 \mathrm{~A} \mathrm{dm}^{-2}\right)$ and lower overpotentials for hydrogen evolution reaction than the normal metals.

(c) Inert metals: metals such as $\mathrm{Co}, \mathrm{Ni}, \mathrm{Pt}$ and $\mathrm{Fe}$. These metals are characterized by low $j_{0}$ values, high $T_{\mathrm{m}}$, and low overpotentials for hydrogen evolution reaction.

Figure 1 gives a schematic presentation of the position of the typical representatives of metals from each of these groups in a function of electrochemical process rate, i.e., the $j_{0}$ value.

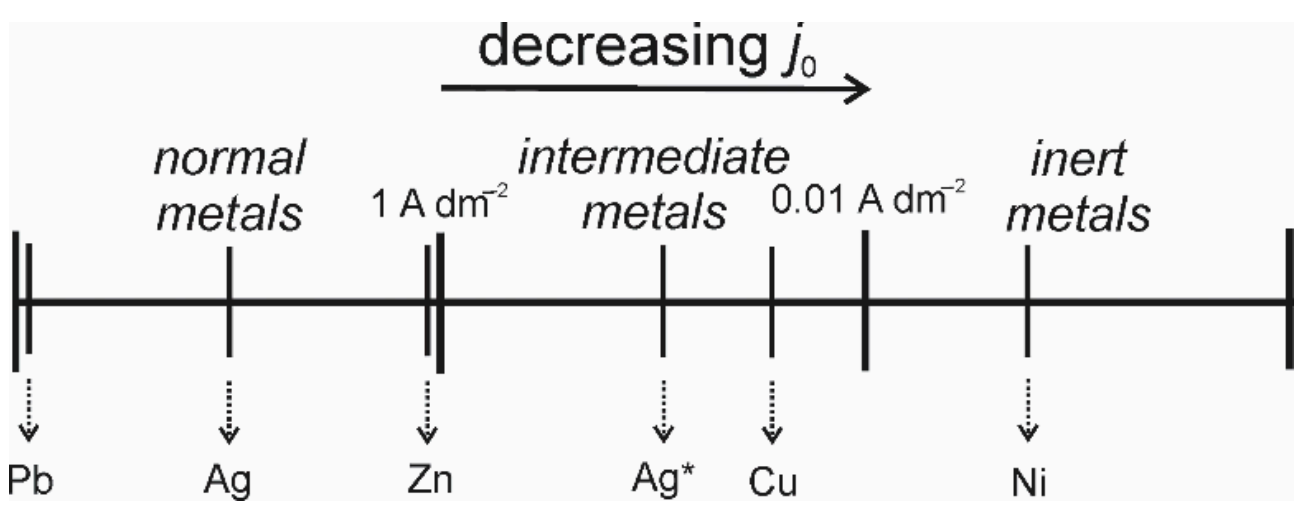

Figure 1. A schematic position of metals on a scale of the exchange current density values. Ag * represents silver electrodeposited from the ammonium electrolyte [15].

Regarding these parameters, the exchange current density and overpotential for hydrogen evolution reaction have a greater influence on the shape of powder particles than the melting point. The shape of dendrites, as the most important form of powder particles, strongly depends on the $j_{0}$ value; thereby, the form of dendrites of metals from the group of the normal metals differs completely from those from the groups of the intermediate and inert metals [10]. The dendrites are formed during electrodeposition in a diffusion control, and in the potentiostatic regime, initiation of dendritic growth occurs at some overpotential belonging to the limiting diffusion current density plateau. In the galvanostatic regime of electrodeposition, for dendritic growth, an initial current density must be larger than the limiting diffusion current density [10].

Hydrogen evolution reaction as a parallel reaction during metal electrolysis can also achieve a significant effect on the shape of powder particles. The spongy-like and the cauliflower-like particles are formed under hydrogen evolution which is intensive enough to cause a stirring of the electrolyte and the change of hydrodynamic conditions in the near-electrode layer $[10,16]$. 
In this review paper, the correlation between crystallographic structure and morphology of powder particles will be presented. Typical metals from each of these three groups: (a) the normal metals: $\mathrm{Pb}$ and $\mathrm{Ag}$ (the basic electrolyte), (b) the intermediate metals: Ag (the ammonium electrolyte) and $\mathrm{Cu}$, and (c) the inert metals: Ni will be analyzed.

The crystal lattices of $\mathrm{Pb}, \mathrm{Ag}, \mathrm{Cu}$, and $\mathrm{Ni}$ belong to face-centered cubic (fcc) type, and the four main reflections ((111), (200), (220), and (311)) will be considered. The crystallographic structure, i.e., the preferred orientation of the powder particles, will be estimated at the semiquantitative level by application of methodology based on the determination of "Texture Coefficient" $(T C(h k l))$ and "Relative Texture Coefficient" $(R T C(h k l))$ [17-20]. The $T C(h k l)$ coefficients larger than 1 indicate the presence of the preferred orientation in the particles. Since the four diffraction peaks corresponding to (111), (200), (220), and (311) crystal planes are analyzed, the $R T C(h k l)$ values larger than $25 \%$ indicate the existence of the preferred orientation in the particles [17-19]. A detailed description of the determination of these coefficients is given in $[18,19]$ and in Appendix A.

\section{The Crystallographic and Electrochemical Definitions of a Dendrite}

From the crystallographic point of view, a dendrite is a skeleton consisting of a stalk or trunk and branches, giving the dendrite the appearance of a tree [21]. The branches can be primary, secondary, etc. The primary branches are developed from the stalk, and the corresponding dendrite is denoted as a dendrite of "P" type. The secondary branches are developed from the primary branches, and the corresponding dendrite is denoted as a dendrite of " $\mathrm{S}$ " type. If the stalk and the branches are in the same plane, the dendrite belongs to the group of the $2 \mathrm{D}$ dendrites.

The electrochemical definition of a dendrite is established by application of the general theory of disperse deposit formation $[10,22]$. The origin of dendrites is of a surface irregularity or protrusion formed in the initial stage of electrodeposition and buried deep in the diffusion layer of the macroelectrode, around which the tip the spherical diffusion layer is formed. Then, the tip of such protrusion grows under the activation control, whereas electrodeposition on the flat part of the electrode surface is under the diffusion control $[10,22,23]$.

\section{Formation of Metal Powders by Electrolysis from Aqueous Electrolytes}

\subsection{The Normal Metals}

With the values of $j_{0}$ which tend to infinity [24], Pb electrodeposition processes belong to ultrafast electrochemical processes. The reported values of $j_{0}$ for Ag in the 100-700 $\mathrm{A} \mathrm{dm}^{-2}$ range were lower than those for $\mathrm{Pb}$ [25]. The common characteristic of all electrodeposition processes featured by the high $j_{0}$ values is the reaching of full diffusion control, i.e., conditions for obtaining powdered (dendritic) deposits at relatively small overpotentials.

Various types of electrolytes based on nitrate [26-29], acetate [27], hydroxide ions [30,31], and tartaric acid [32] are used for Pb electrodeposition. The nitrate electrolytes belong to a group of the basic electrolytes, whereas the other electrolytes are from the group of complex electrolytes. The most often used basic type of electrolyte for Ag electrodeposition is based on nitrates $[18,33,34]$.

The polarization curves normalized to the limiting diffusion current density values for $\mathrm{Pb}$ electrodeposition from the basic (nitrate) and the complex (acetate) electrolytes and for $\mathrm{Ag}$ from the basic (nitrate) electrolyte are presented in Figure 2. The plateaus of the limiting diffusion current density were in the ranges of $28.5-55 \mathrm{mV}$ for the nitrate, $33-70 \mathrm{mV}$ for the acetate electrolyte of $\mathrm{Pb}[27,35]$, and 70-110 $\mathrm{mV}$ for the nitrate electrolyte of $\mathrm{Ag}[18,34]$. 


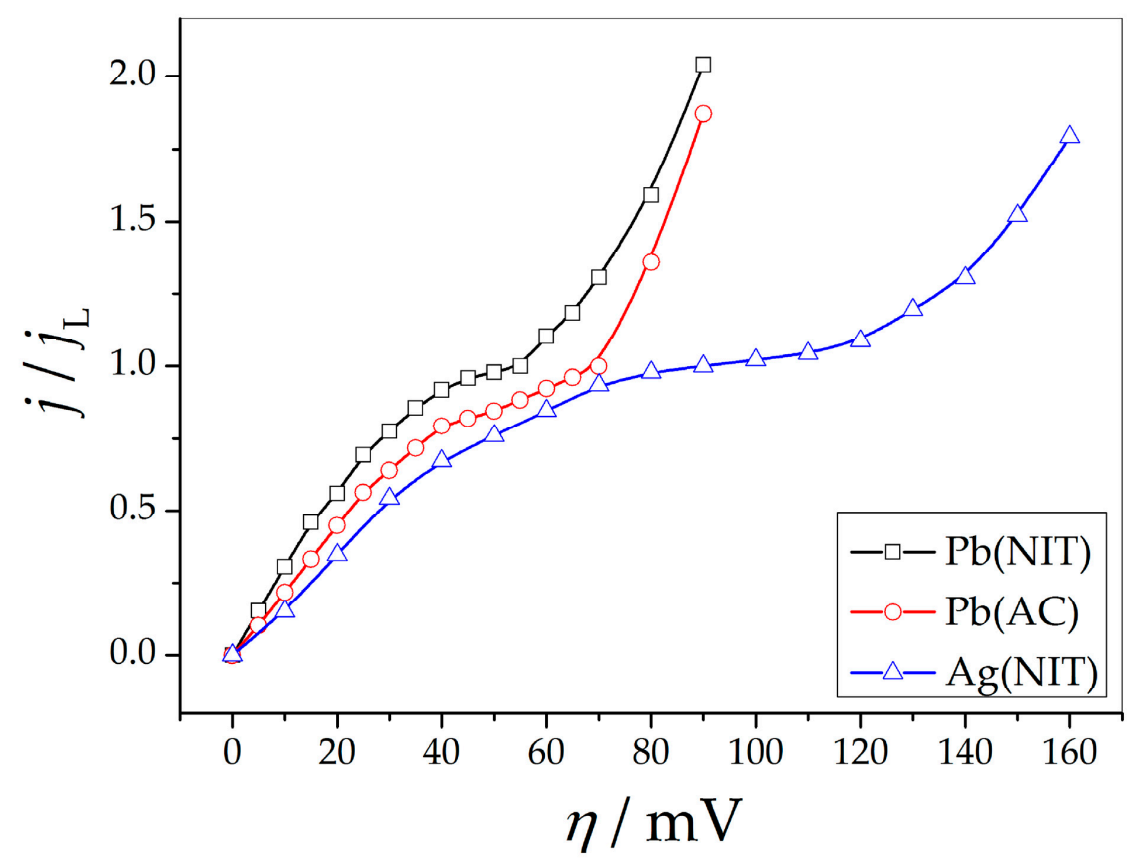

Figure 2. The polarization curves normalized to the limiting diffusion current density values for electrodeposition of $\mathrm{Pb}$ from the nitrate $(\mathrm{Pb}(\mathrm{NIT}))$ and the acetate $(\mathrm{Pb}(\mathrm{AC}))$ electrolytes and for $\mathrm{Ag}$ electrodeposition from the nitrate electrolyte (Ag(NIT)).

\subsubsection{Lead}

Different two-dimensional (2D) fern-like dendrites are produced by $\mathrm{Pb}$ electrodeposition from the nitrate (Figure $3 a, b$ ) and the acetate (Figure $3 c, d$ ) electrolytes at the overpotential outside the plateau of the limiting diffusion current density $(\eta=90 \mathrm{mV})$. The 2D dendrites obtained from the acetate electrolyte had a considerably more branchy morphology than those obtained from the nitrate electrolyte. Following the definition of a dendrite given by Wranglen [21], it is clear that the fern-like dendrites of $\mathrm{Pb}$ produced from the nitrate solution belong to the $2 \mathrm{D}(\mathrm{P})$ type, while those obtained from the acetate solution belong to the $2 \mathrm{D}(\mathrm{S})$ type. This change in the shape of dendrites can be attributed to complex formation between acetate and $\mathrm{Pb}$ (II) ions $[27,35]$.

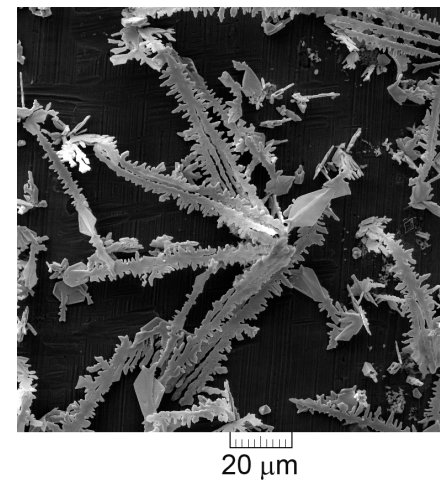

(a)

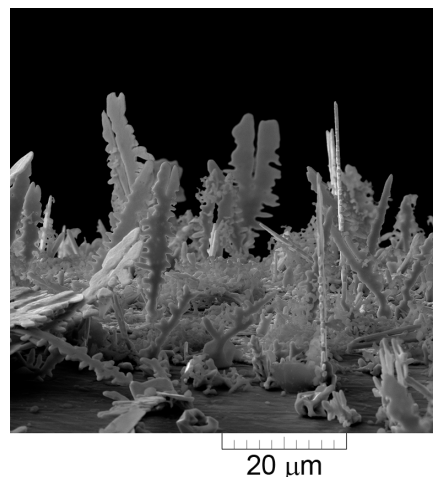

(b)

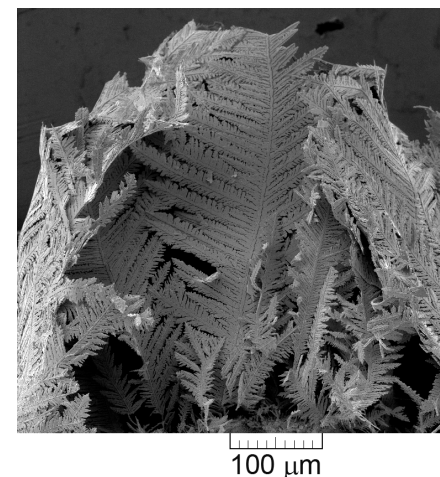

(c)

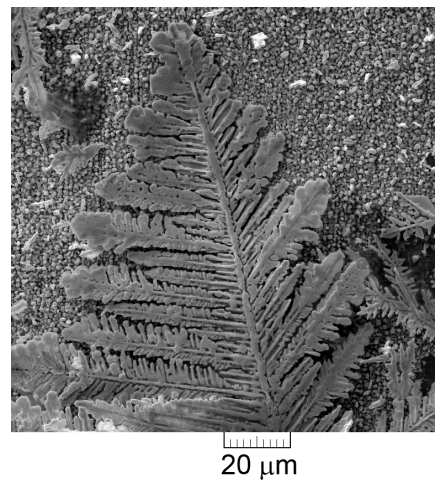

(d)

Figure 3. Morphologies of $\mathrm{Pb}$ powder particles produced by electrodeposition from $(\mathbf{a}, \mathbf{b})$ the nitrate electrolyte $(0.10 \mathrm{M}$ $\left.\mathrm{Pb}\left(\mathrm{NO}_{3}\right)_{2}+2.0 \mathrm{M} \mathrm{NaNO}_{3}\right)$ and $(\mathbf{c}, \mathbf{d})$ the acetate electrolyte $\left(0.10 \mathrm{M} \mathrm{Pb}\left(\mathrm{CH}_{3} \mathrm{COO}\right)_{2}+1.5 \mathrm{M} \mathrm{NaCH}_{3} \mathrm{COO}+0.15 \mathrm{M} \mathrm{CH} 3 \mathrm{COOH}\right)$. Overpotential of electrodeposition $(\eta)$ : $90 \mathrm{mV}$ [20]. 
The X-ray diffraction (XRD) patterns of $\mathrm{Pb}$ particles produced under the same conditions, together with $\mathrm{Pb}$ standard (04-0686), are shown in Figure 4. The diffraction peaks at $2 \theta$ angles of $31.3,36.3,52.2$, and $62.1^{\circ}$ belong to (111), (200), (220), and (311) crystal planes, confirming the fcc crystal lattice of $\mathrm{Pb}$ [20]. In both types of particles, $\mathrm{Pb}$ crystallites were predominantly oriented in the (111) plane. The values of TC $(h k l)$ and $R T C(h k l)$ coefficients calculated with an aim of precise determination of the preferred orientation of $\mathrm{Pb}$ particles are given in Table 1.

The meaning of $R$ in Table 1 , as well as in later presented tables, is given in Appendix A. Both powders possess the strong (111) preferred orientation, but it is important to note the larger contribution of Pb crystallites oriented in the (200), (220), and (311) planes in the particles synthesized from the acetate than in those produced in the nitrate solution.

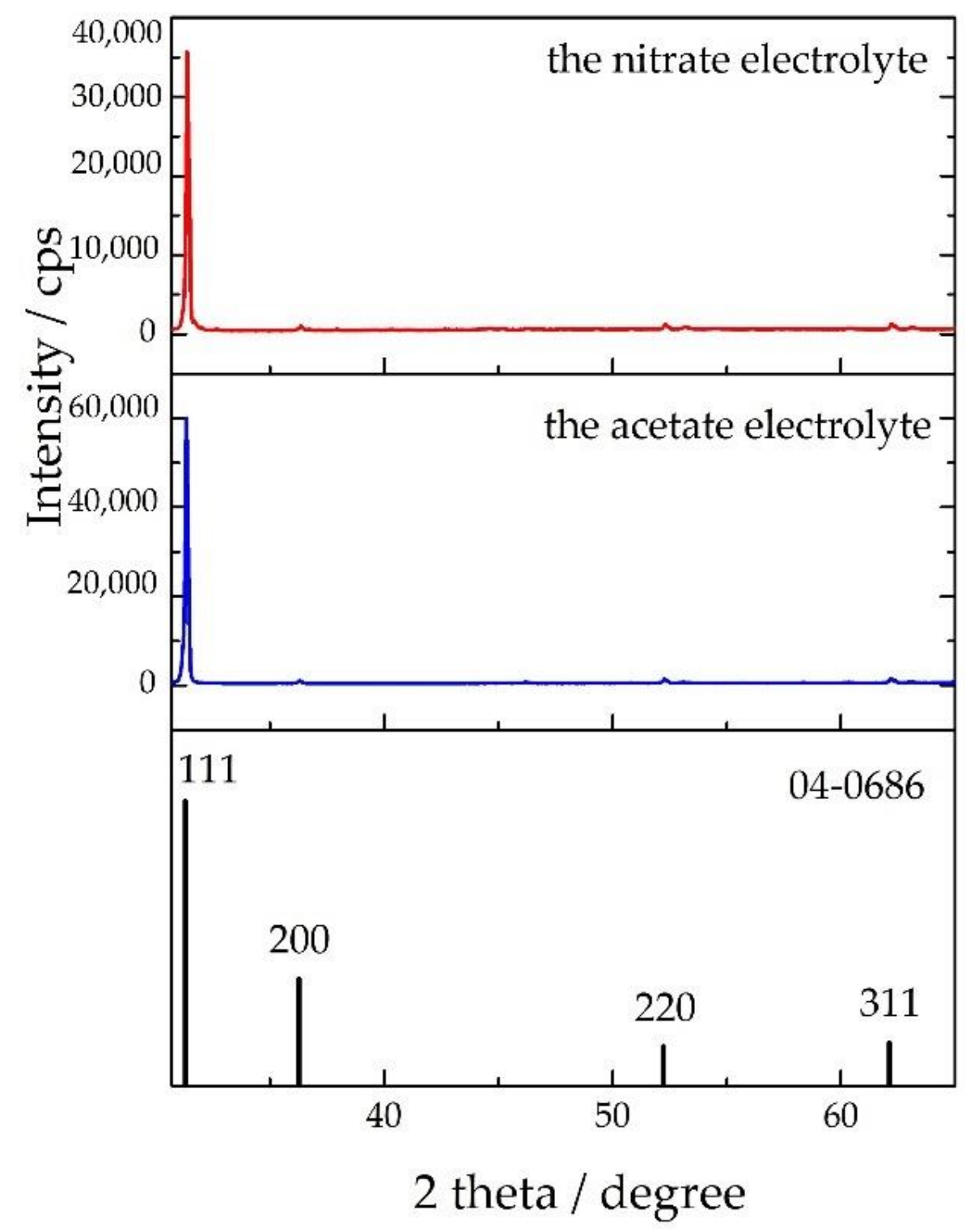

Figure 4. The $\mathrm{XRD}$ (X-ray diffraction) patterns of $\mathrm{Pb}$ particles produced at an overpotential $(\eta)$ of $90 \mathrm{mV}$ from the nitrate and the acetate electrolytes and $\mathrm{Pb}$ standard (04-0686). Cps: counts per second. 
Table 1. Texture calculations for $\mathrm{Pb}$ powders produced potentiostatically at $\eta$ of $90 \mathrm{mV}$ from the nitrate and the acetate electrolytes (TC: texture coefficient. RTC: relative texture coefficient. NIT: the nitrate electrolyte. AC: the acetate electrolyte. $\mathrm{s}$ : $\mathrm{Pb}$ standard).

\begin{tabular}{|c|c|c|c|c|c|c|c|}
\hline \multirow{2}{*}{$\begin{array}{l}\text { Plane } \\
(h k l)\end{array}$} & \multicolumn{2}{|c|}{$R(\mathrm{in} \%)$} & \multirow{2}{*}{$\begin{array}{c}R_{\mathrm{s}} \\
\text { (in \%) }\end{array}$} & \multicolumn{2}{|c|}{$T C$} & \multicolumn{2}{|c|}{$R T C$ (in\%) } \\
\hline & $R_{\mathrm{NIT}}$ & $R_{\mathrm{AC}}$ & & $T C_{\mathrm{NIT}}$ & $T C_{\mathrm{AC}}$ & $R T C_{\mathrm{NIT}}$ & $R T C_{\mathrm{AC}}$ \\
\hline$(111)$ & 89.7 & 83.5 & 46.9 & 1.91 & 1.78 & 75.5 & 63.8 \\
\hline$(200)$ & 3.1 & 4.4 & 23.5 & 0.13 & 0.19 & 5.2 & 6.8 \\
\hline$(220)$ & 3.6 & 5.8 & 14.6 & 0.25 & 0.40 & 9.9 & 14.3 \\
\hline$(311)$ & 3.6 & 6.3 & 15.0 & 0.24 & 0.42 & 9.4 & 15.1 \\
\hline
\end{tabular}

\subsubsection{Silver (The Nitrate Electrolyte)}

The shifting of the plateau of the limiting diffusion current density towards the higher overpotentials clearly proves that the Ag electrodeposition processes from the nitrate electrolyte are slower than those for $\mathrm{Pb}$.

The needle-like dendrites together with granules of various shape are obtained at the overpotential inside the plateau ( $\eta=90 \mathrm{mV}$; Figure $5 \mathrm{a}, \mathrm{b})$, whereas the very branchy $2 \mathrm{D}$ fern-like dendrites were obtained at the overpotential outside the plateau $(\eta=150 \mathrm{mV}$; Figure $5 c, d$ ) of the limiting diffusion current density [34]. Similar forms to those obtained at $\eta$ of $90 \mathrm{mV}$ (the mixture of the needle-like dendrites and granules (crystals) of regular and irregular shape) were also produced galvanostatically at a current density 1.5 times larger than the limiting diffusion current density $\left(j=14.4 \mathrm{~mA} \mathrm{~cm}^{-2}\right.$; Figure $\left.5 \mathrm{e}, \mathrm{f}\right)$ [18].

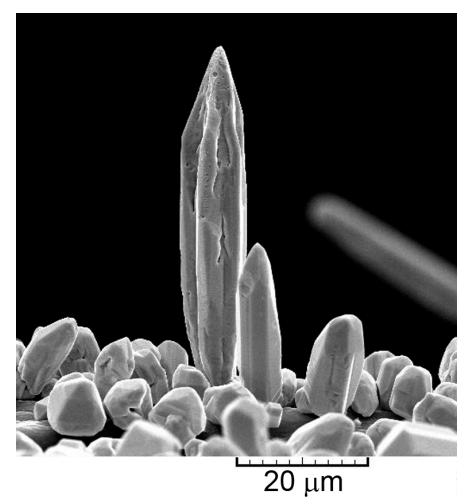

(a)

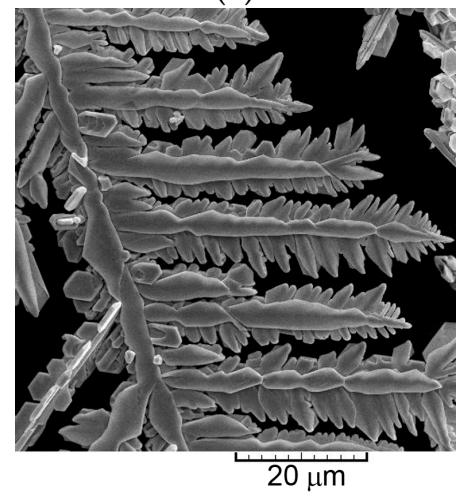

(d)

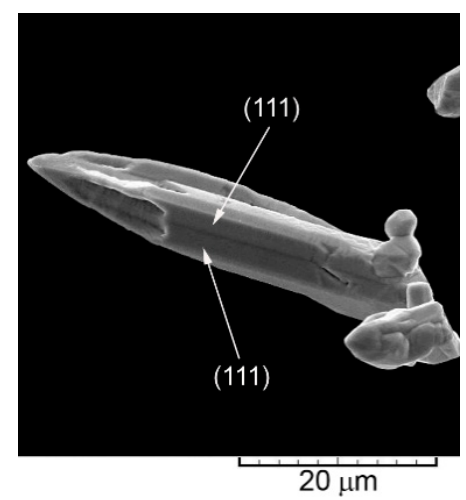

(b)

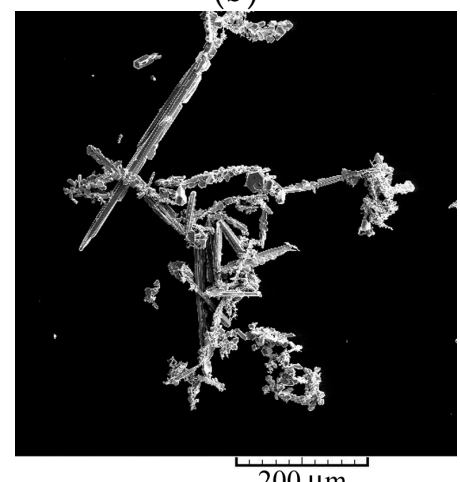

(e)

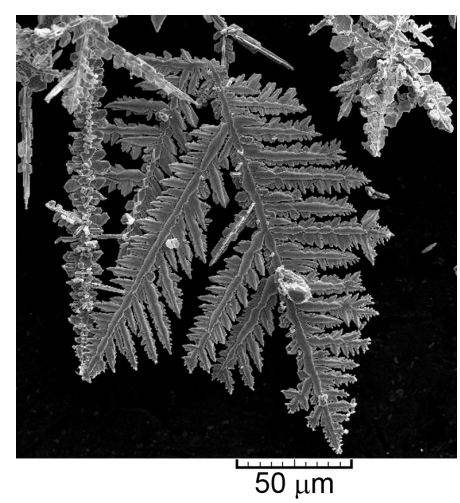

(c)

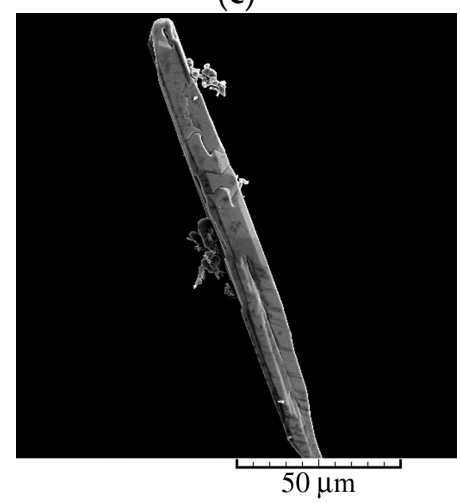

(f)

Figure 5. Morphologies of $\mathrm{Ag}$ powder particles produced by electrodeposition from the nitrate electrolyte (0.10 $\mathrm{M}$ $\mathrm{AgNO}_{3}$ in $\left.2.0 \mathrm{M} \mathrm{NaNO}_{3}\right)$ at overpotentials of $(\mathbf{a}, \mathbf{b}) \eta=90 \mathrm{mV}$ and $(\mathbf{c}, \mathbf{d}) \eta=150 \mathrm{mV}$ and at a current density of $(\mathbf{e}, \mathbf{f})$ $j=14.4 \mathrm{~mA} \mathrm{~cm}^{-2}$ ([18] and reprinted from [34] with permission from Elsevier). 
The XRD patterns of these particles (Figure 6) showed the predominant orientation of Ag crystallites in the (111) plane. The diffraction maximum observed at $2 \theta$ angles of 38.1, $44.3,64.4$, and $77.5^{\circ}$ corresponded to (111), (200), (220), and (311) crystal planes, confirming the fact that Ag crystallizes in fcc crystal lattice [18,34]. The calculated TC $(h k l)$ and $R T C(h k l)$ coefficients are given in Table 2.

The Ag particles produced at $90 \mathrm{mV}$ (the dominant presence of the needle-like forms) possessed the strong (111) preferred orientation. Aside from the dominant orientation of Ag crystallites in this plane, the fern-like dendrites obtained at $150 \mathrm{mV}$ also showed the weak (200) preferred orientation [34]. The (111) preferred orientation is also observed for galvanostatically synthesized particles at $14.4 \mathrm{~mA} \mathrm{~cm}^{-2}$.

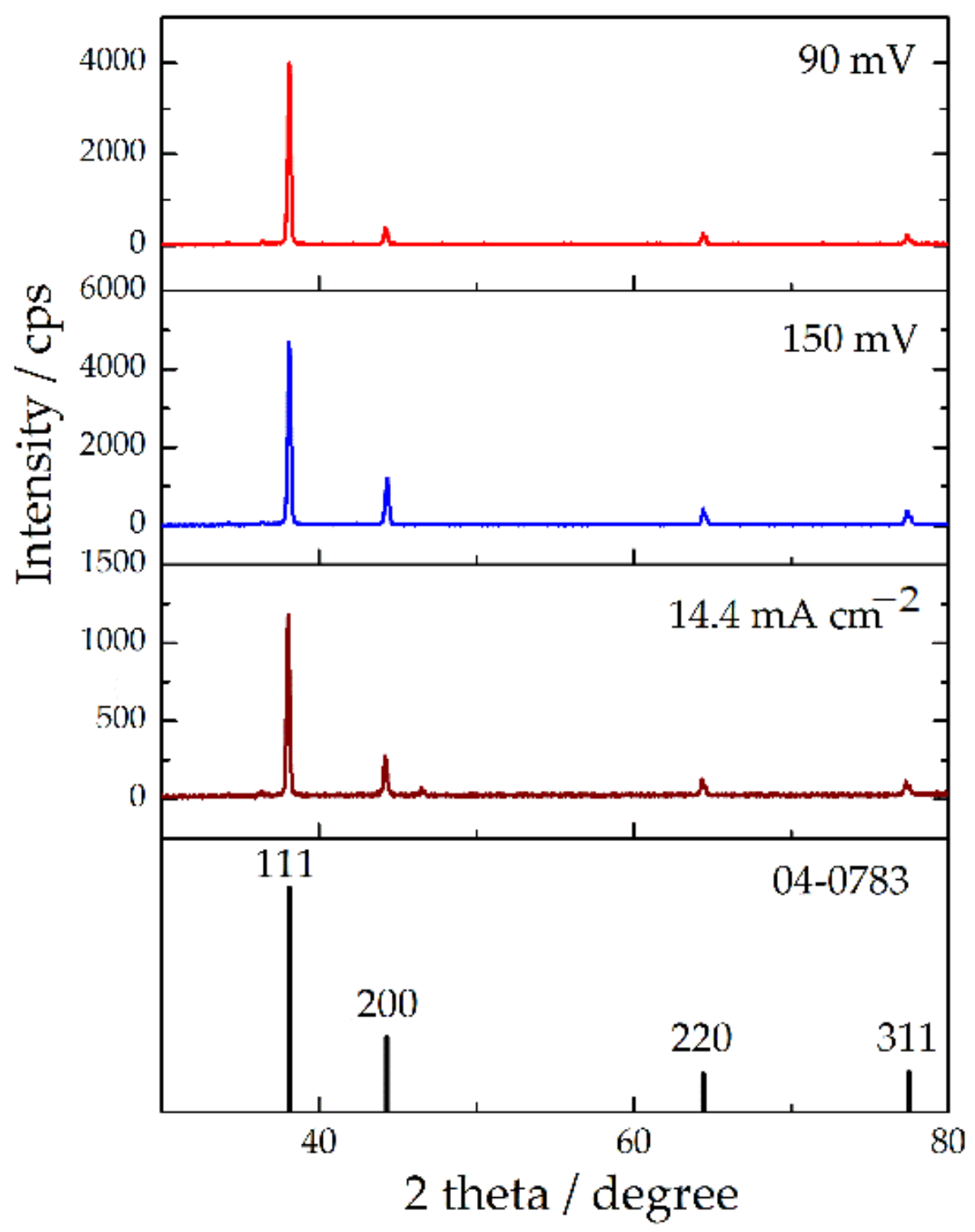

Figure 6. The XRD patterns of Ag particles obtained from the nitrate electrolyte at $\eta$ of 90 and $150 \mathrm{mV}$ and at $j$ of $14.4 \mathrm{~mA} \mathrm{~cm}^{-2}$ and $\mathrm{Ag}$ standard (04-0783) ([18] and reprinted from [34] with permission from Elsevier). 
Table 2. Texture calculations for Ag powders produced potentiostatically at $\eta$ of 90 and $150 \mathrm{mV}$ and galvanostatically at $j$ of $14.4 \mathrm{~mA} \mathrm{~cm}^{-2}\left(90-\eta=90 \mathrm{mV} ; 150-\eta=150 \mathrm{mV} ; 14.4-j=14.4 \mathrm{~mA} \mathrm{~cm}^{-2}\right.$; $\mathrm{s}-\mathrm{Ag}$ standard) ([18] and reprinted from [34] with permission from Elsevier).

\begin{tabular}{|c|c|c|c|c|c|c|c|c|c|c|}
\hline \multirow{2}{*}{$\begin{array}{c}\text { Plane } \\
(h k l)\end{array}$} & \multicolumn{3}{|c|}{$R(\mathrm{in} \%)$} & \multirow{2}{*}{$\underset{(\mathrm{in} \%)}{R_{\mathrm{s}}}$} & \multicolumn{3}{|c|}{$T C$} & \multicolumn{3}{|c|}{ RTC (in\%) } \\
\hline & $R_{90}$ & $R_{150}$ & $R_{14.4}$ & & $T C_{90}$ & $T C_{150}$ & $T C_{14.4}$ & $R T C_{90}$ & $R T C_{150}$ & $R T C_{14.4}$ \\
\hline (111) & 82.2 & 70.1 & 69.4 & 52.4 & 1.57 & 1.34 & 1.32 & 58.1 & 43.4 & 41.6 \\
\hline$(200)$ & 7.7 & 18.1 & 16.3 & 20.9 & 0.37 & 0.87 & 0.78 & 13.7 & 28.1 & 24.6 \\
\hline$(220)$ & 5.2 & 6.3 & 7.4 & 13.1 & 0.40 & 0.48 & 0.56 & 14.8 & 15.6 & 17.7 \\
\hline$(311)$ & 4.9 & 5.5 & 6.9 & 13.6 & 0.36 & 0.40 & 0.51 & 13.4 & 12.9 & 16.1 \\
\hline
\end{tabular}

\subsection{The Intermediate Metals}

$\mathrm{Cu}, \mathrm{Ag}$ (if the ammonium electrolyte is used for electrodeposition), and Au are the typical representatives of the group of the intermediate metals. The $j_{0}$ values are 0.025 $\mathrm{A} \mathrm{dm}^{-2}$ for $\mathrm{Ag}$ [36] and 0.011-0.032 $\mathrm{A} \mathrm{dm}^{-2}$ for $\mathrm{Cu}[10,37]$.

The polarization curves normalized to the limiting diffusion current densities for electrodeposition of Ag from the ammonium electrolyte and $\mathrm{Cu}$ are shown in Figure 7. The polarization curves are very similar to each other, with the plateaus of the limiting diffusion current density in the $250-700 \mathrm{mV}$ range for the ammonium electrolyte of $\mathrm{Ag}$ and the $300-750 \mathrm{mV}$ range for $\mathrm{Cu}$.

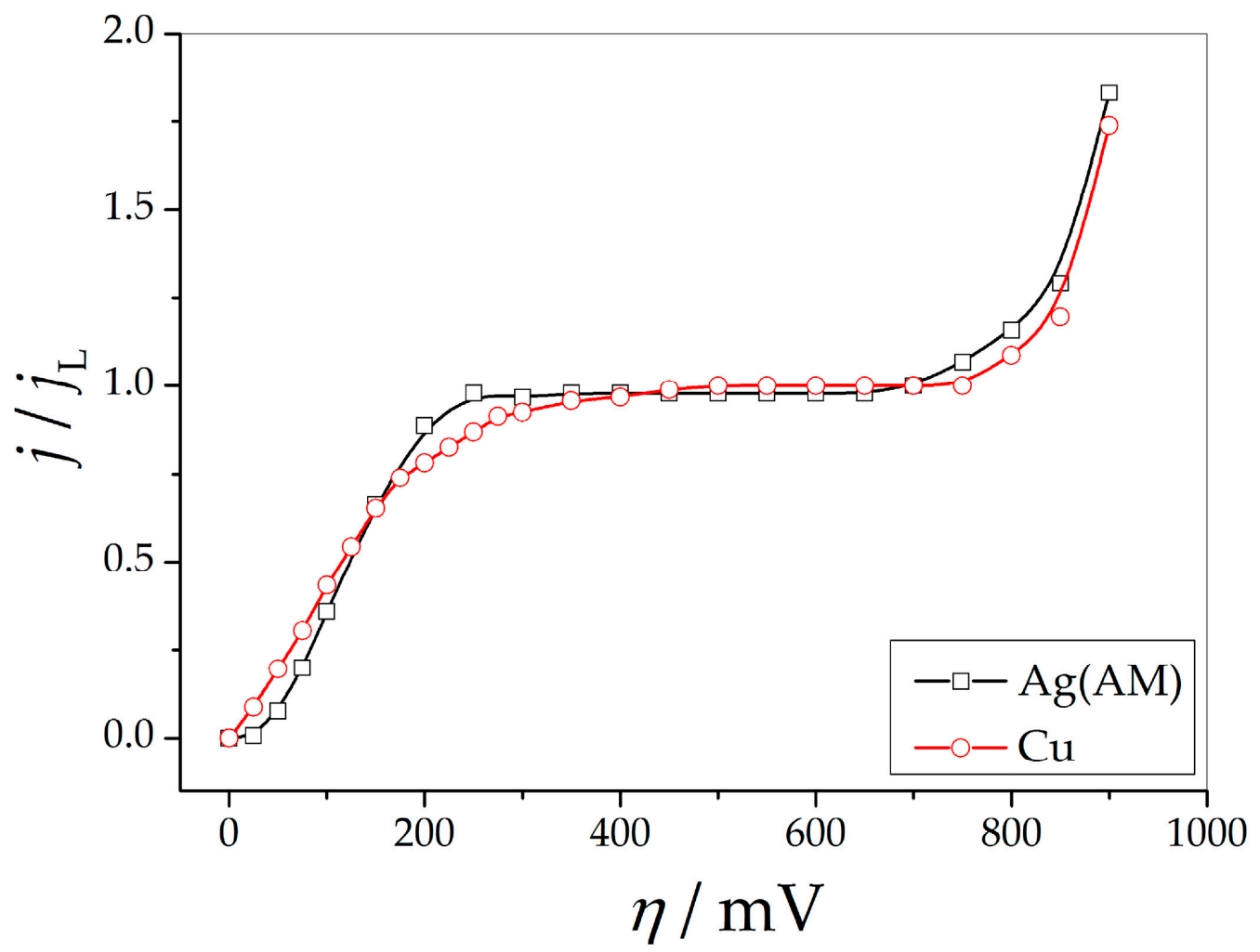

Figure 7. The polarization curves normalized to the limiting diffusion current density values for electrodeposition of $\mathrm{Ag}$ from the ammonium ( $\mathrm{Ag}(\mathrm{AM})$ ) electrolyte and for $\mathrm{Cu}$ electrodeposition from the sulfate electrolyte. 


\subsubsection{Silver (The Ammonium Electrolyte)}

The three-dimensional (3D) pine-like dendrites were obtained by electrodeposition from the ammonium solution at the overpotentials both inside $(\eta=625 \mathrm{mV}$; Figure $8 \mathrm{a}, \mathrm{b})$ and outside $(\eta=925 \mathrm{mV}$; Figure $8 \mathrm{c}, \mathrm{d})$ the plateau of the limiting diffusion current density [34]. The only difference was in the degree of their ramification; the 3D dendrites obtained at $925 \mathrm{mV}$ were more ramified than those obtained at $625 \mathrm{mV}$. The 3D pine-like dendrites were also produced using a galvanostatic regime of electrolysis at a current density 1.5 times larger than the limiting diffusion current density (Figure 8e,f) [18]. This dendrite type was constructed from approximately spherical grains, the size of which decreased with the increase in overpotential of the electrodeposition with a tendency to approach nano dimensions. The tips of both stalk and branches of these dendrites were sharp.

The XRD patterns of the powder particles produced from the ammonium solution, together with Ag standard (04-0783), are presented in Figure 9. Similar to those produced from the nitrate electrolyte, the Ag crystallites were predominantly oriented in the (111) plane. However, at the first sight, the larger contribution of crystallites oriented in the (200), (220), and (311) planes in these particles than in those produced from the nitrate solution can be noticed. The values of $T C(h k l)$ and $R T C(h k l)$ coefficients for the particles produced in the ammonium solution are given in Table 3.

Analyzing the calculated values, it follows that the 3D pine-like dendrites synthesized at $625 \mathrm{mV}$ showed the (111) preferred orientation. On the other hand, the values of these coefficients for the 3D pine-like dendrites obtained potentiostatically at $925 \mathrm{mV}$ and galvanostatically at $13.05 \mathrm{~mA} \mathrm{~cm}^{-2}$ group themselves around $1(T C(h k l))$ and $25 \%$ $(R T C(h k l))$, indicating a random orientation of Ag crystallites in them.

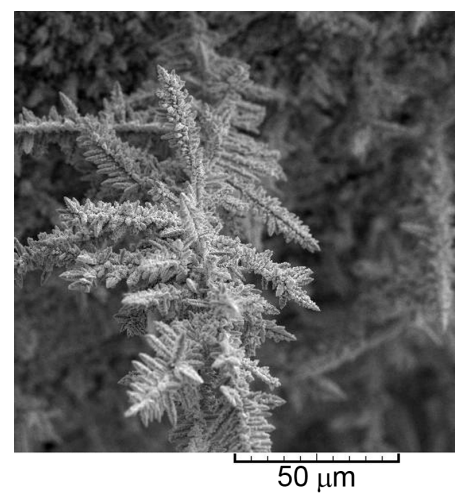

(a)

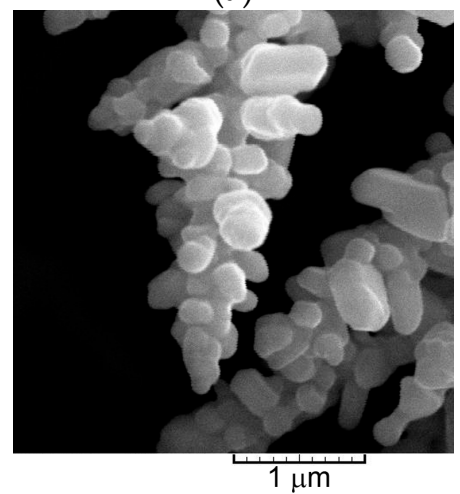

(d)

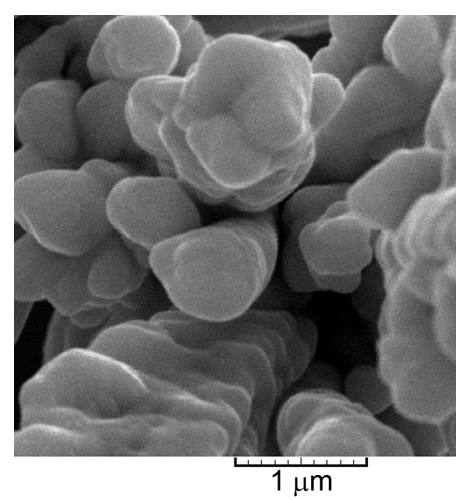

(b)

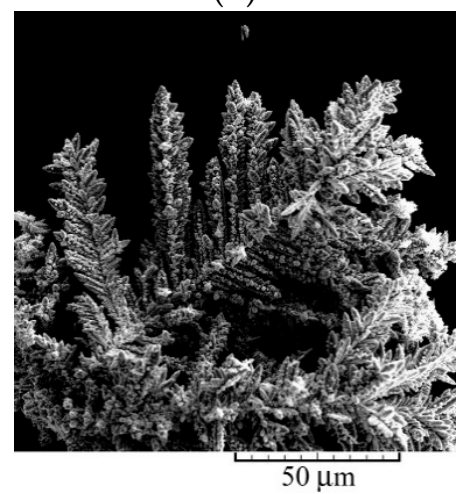

(e)

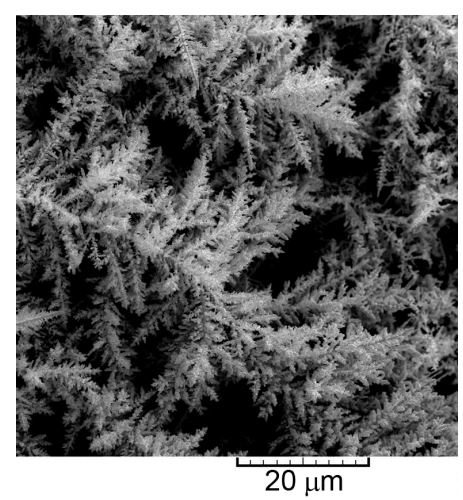

(c)

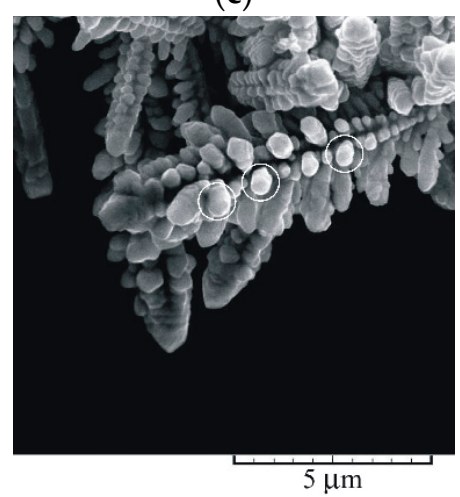

(f)

Figure 8. The 3D pine-like dendrites produced by electrodeposition from the ammonium electrolyte $\left(0.10 \mathrm{M} \mathrm{AgNO}_{3}\right.$ in $0.50 \mathrm{M}\left(\mathrm{NH}_{4}\right)_{2} \mathrm{SO}_{4}$ with the addition of $\mathrm{NH}_{3}$ in excess to dissolve silver sulfate precipitate) at overpotentials of $(\mathbf{a}, \mathbf{b})$ $625 \mathrm{mV}$ and (c,d) $925 \mathrm{mV}$ and at a current density of (e,f) $13.05 \mathrm{~mA} \mathrm{~cm}^{-2}$ ([18] and reprinted from [34] with permission from Elsevier). 


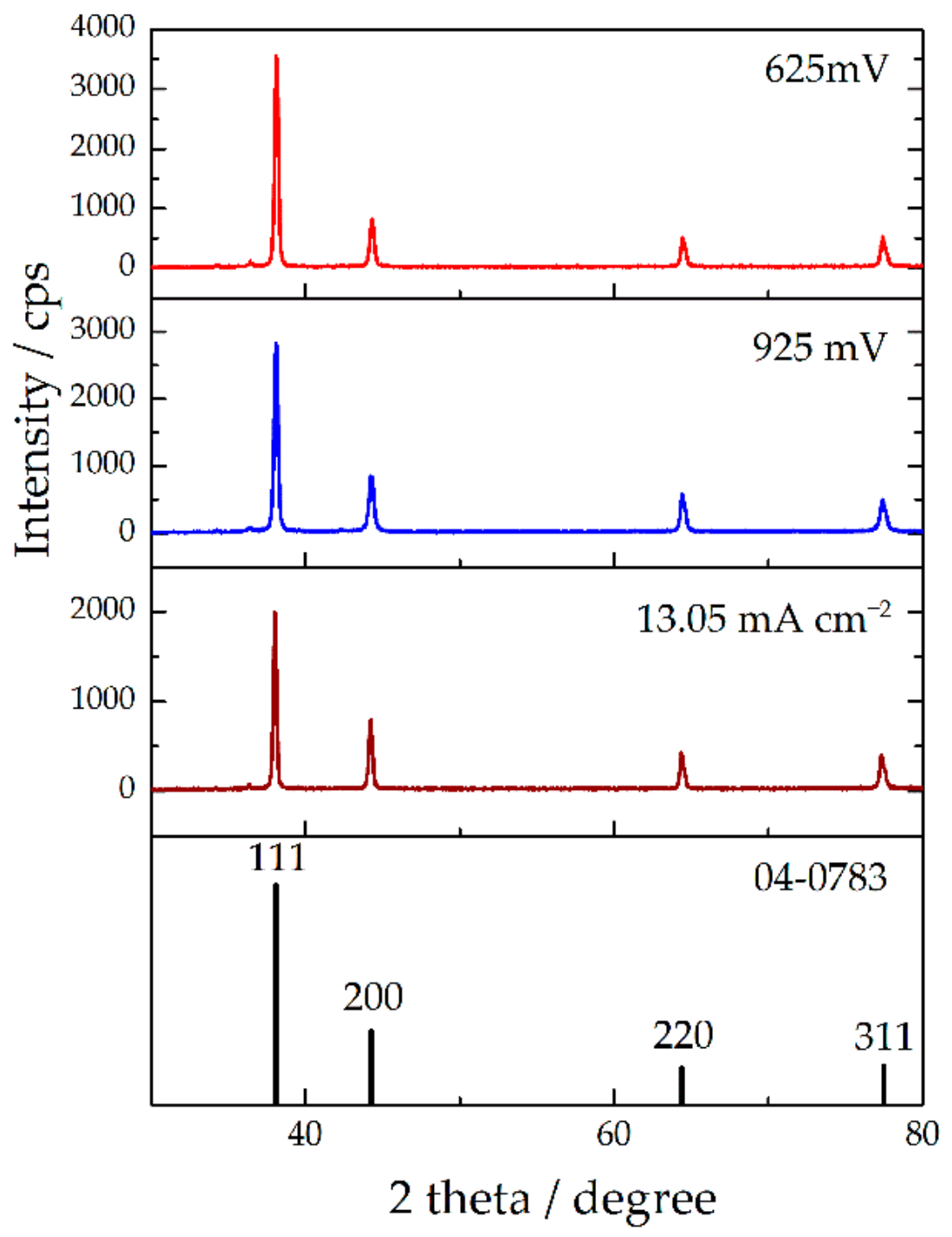

Figure 9. The $\mathrm{XRD}$ patterns of $\mathrm{Ag}$ particles obtained from the ammonium electrolyte at overpotentials of 625 and $925 \mathrm{mV}$ and at a current density of $13.05 \mathrm{~mA} \mathrm{~cm}^{-2}$ and Ag standard (04-0783) ([18] and reprinted from [34] with permission from Elsevier).

Table 3. Texture calculations for Ag powders produced potentiostatically at $\eta$ of 625 and $925 \mathrm{mV}$ and galvanostatically at $j$ of $13.05 \mathrm{~mA} \mathrm{~cm}{ }^{-2}(625-\eta=625 \mathrm{mV}$; $925-\eta=925 \mathrm{mV}$; $13.05-$ $j=13.05 \mathrm{~mA} \mathrm{~cm}^{-2}$; s-Ag standard) ([18] and reprinted from [34] with permission from Elsevier).

\begin{tabular}{|c|c|c|c|c|c|c|c|c|c|c|}
\hline \multirow{2}{*}{$\begin{array}{c}\text { Plane } \\
(h k l)\end{array}$} & \multicolumn{3}{|c|}{$R(\mathrm{in} \%)$} & \multirow{2}{*}{$\begin{array}{c}R_{\mathrm{s}} \\
(\mathrm{in} \%)\end{array}$} & \multicolumn{3}{|c|}{$T C$} & \multicolumn{3}{|c|}{$R T C$ (in \%) } \\
\hline & $R_{625}$ & $R_{925}$ & $R_{13.05}$ & & $T C_{625}$ & $T C_{925}$ & $T C_{13.05}$ & $R T C_{625}$ & $R T C_{925}$ & $R T C_{13.05}$ \\
\hline$(111)$ & 65.9 & 59.2 & 54.9 & 52.4 & 1.26 & 1.13 & 1.05 & 37.0 & 30.5 & 27.2 \\
\hline$(200)$ & 15.1 & 17.8 & 21.9 & 20.9 & 0.72 & 0.85 & 1.05 & 21.1 & 23.0 & 27.2 \\
\hline$(220)$ & 9.4 & 12.2 & 11.9 & 13.1 & 0.72 & 0.93 & 0.93 & 21.1 & 25.1 & 24.1 \\
\hline$(311)$ & 9.6 & 10.8 & 11.3 & 13.6 & 0.71 & 0.79 & 0.83 & 20.8 & 21.4 & 21.5 \\
\hline
\end{tabular}

\subsubsection{Copper}

The 3D pine-like dendrites built from stalk and branches like a corncob with sharp tips were obtained at the overpotential inside the plateau of the limiting diffusion current density $(\eta=625 \mathrm{mV}$; Figure 10a-c) [38]. The cauliflower-like particles are produced at an overpotential outside the plateau $(\eta=925 \mathrm{mV}$; Figure $10 \mathrm{~d})$. They were obtained by removing the electrodeposit from the honeycomb-like structure shown in Figure 10e. The 
honeycomb-like structure is obtained in conditions of vigorous hydrogen evolution and was built from holes originating from detached hydrogen bubbles and cauliflower-like grains agglomerates around them [10,16]. At the micro level, both the 3D pine-like dendrites and the cauliflower-like particles consist of small agglomerates of approximately spherical grains (Figure 10c,f), the size of which decreased with the increase in the overpotential. Hence, in spite of similar polarization curves for $\mathrm{Ag}$ and $\mathrm{Cu}$ (Figure 7), morphologies of $\mathrm{Ag}$ and $\mathrm{Cu}$ particles obtained at the overpotential outside the plateau of the limiting diffusion current density $(\eta=925 \mathrm{mV})$ were very different at the macro level. This difference was caused by vigorous hydrogen evolution as a parallel reaction in the case of copper.

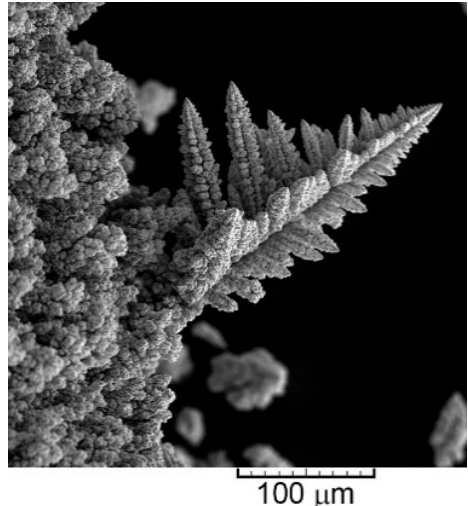

(a)

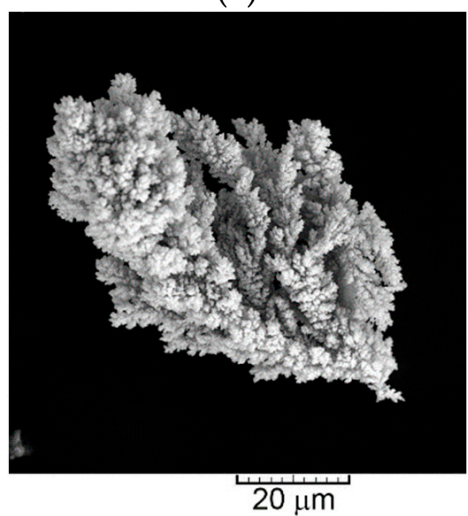

(d)

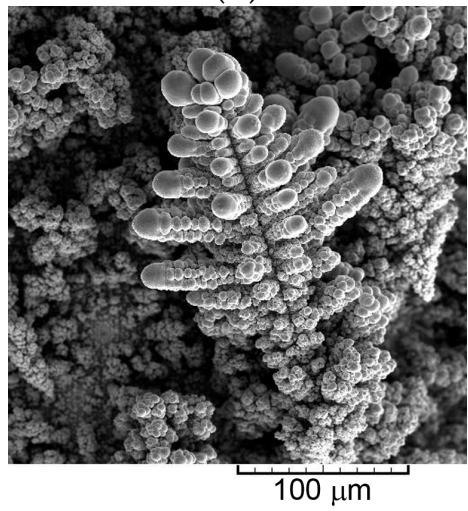

(g)

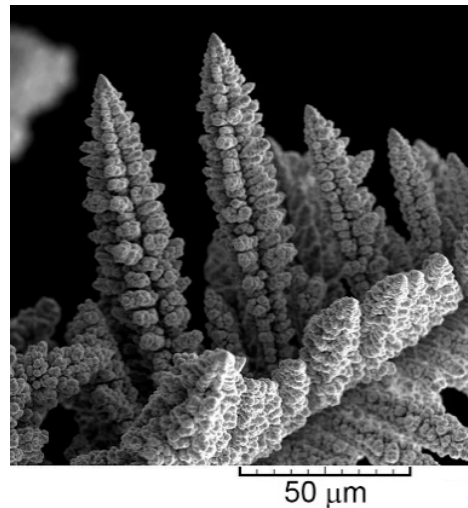

(b)

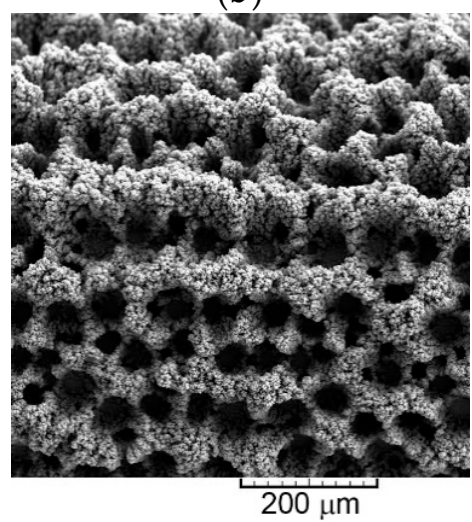

(e)

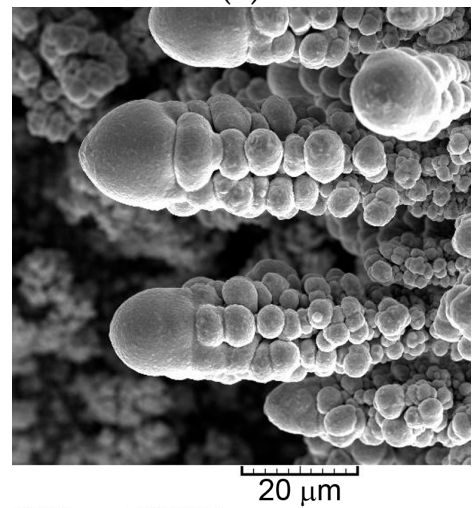

(h)

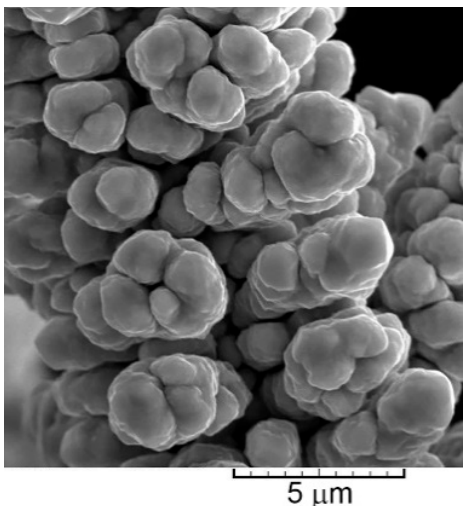

(c)

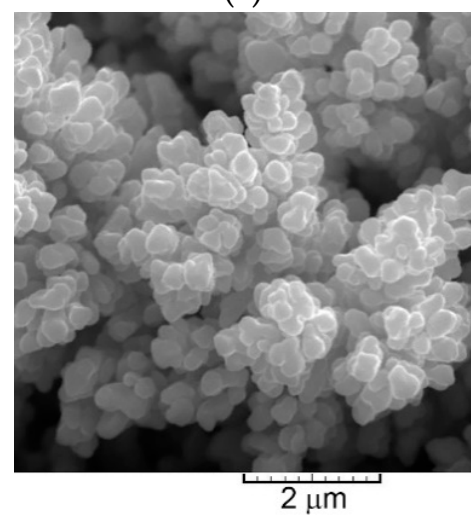

(f)

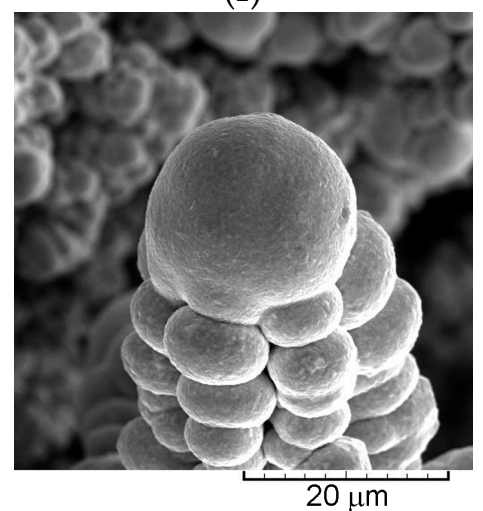

(i)

Figure 10. The powder particles produced by Cu electrodeposition from $0.10 \mathrm{M} \mathrm{CuSO}_{4}$ in $0.50 \mathrm{M} \mathrm{H}_{2} \mathrm{SO}_{4}$ at $\eta$ of $(\mathbf{a}-\mathbf{c}) 625 \mathrm{mV}$ and $(\mathbf{d}-\mathbf{f}) 925 \mathrm{mV}$ and at $j$ of $(\mathbf{g}-\mathbf{i}) 14.4 \mathrm{~mA} \mathrm{~cm}^{-2}$ ([19] and reprinted from [38] with permission from Elsevier). 
The 3D dendrites obtained galvanostatically at a current density 1.5 times larger than the limiting diffusion current density $\left(j=14.4 \mathrm{~mA} \mathrm{~cm}^{-2}\right.$; Figure $\left.10 \mathrm{~g}-\mathrm{i}\right)$ were to a certain extent different from those obtained at $625 \mathrm{mV}$. Although they kept a pine-like form, the tips of trunk and branches, as well as corncob-like branches, were constructed from globules [19]. The size of globules having the shape of almost ideal spheres was from 3 to $5 \mu \mathrm{m}$ in the branches to $10 \mu \mathrm{m}$ at the tops of both trunk and branches.

The XRD patterns of the $\mathrm{Cu}$ particles produced by both potentiostatic and galvanostatic regimes of electrolysis, together with $\mathrm{Cu}$ standard (04-0836), are presented in Figure 11. Copper crystallizes in fcc crystal lattice, which is confirmed by diffraction peaks at $2 \theta$ angles of $43.3,50.4,74.1$, and $89.9^{\circ}$ corresponding to (111), (200), (220), and (311) crystal planes. The values of $T C(h k l)$ and $R T C(h k l)$ coefficients calculated by analysis of XRD data are summarized in Table 4. Analyzing the values given in this table, it can be concluded that the $T C(h k l)$ coefficients are very close to 1 , while $R T C(h k l)$ coefficients are around $25 \%$, indicating the random orientation of $\mathrm{Cu}$ crystallites in all types of the particles. The random orientation of $\mathrm{Cu}$ powder particles of various morphologies at the macro level can be attributed to their similar morphology at the micro level, i.e., approximately spherical $\mathrm{Cu}$ grains constructing all three types of the particles.

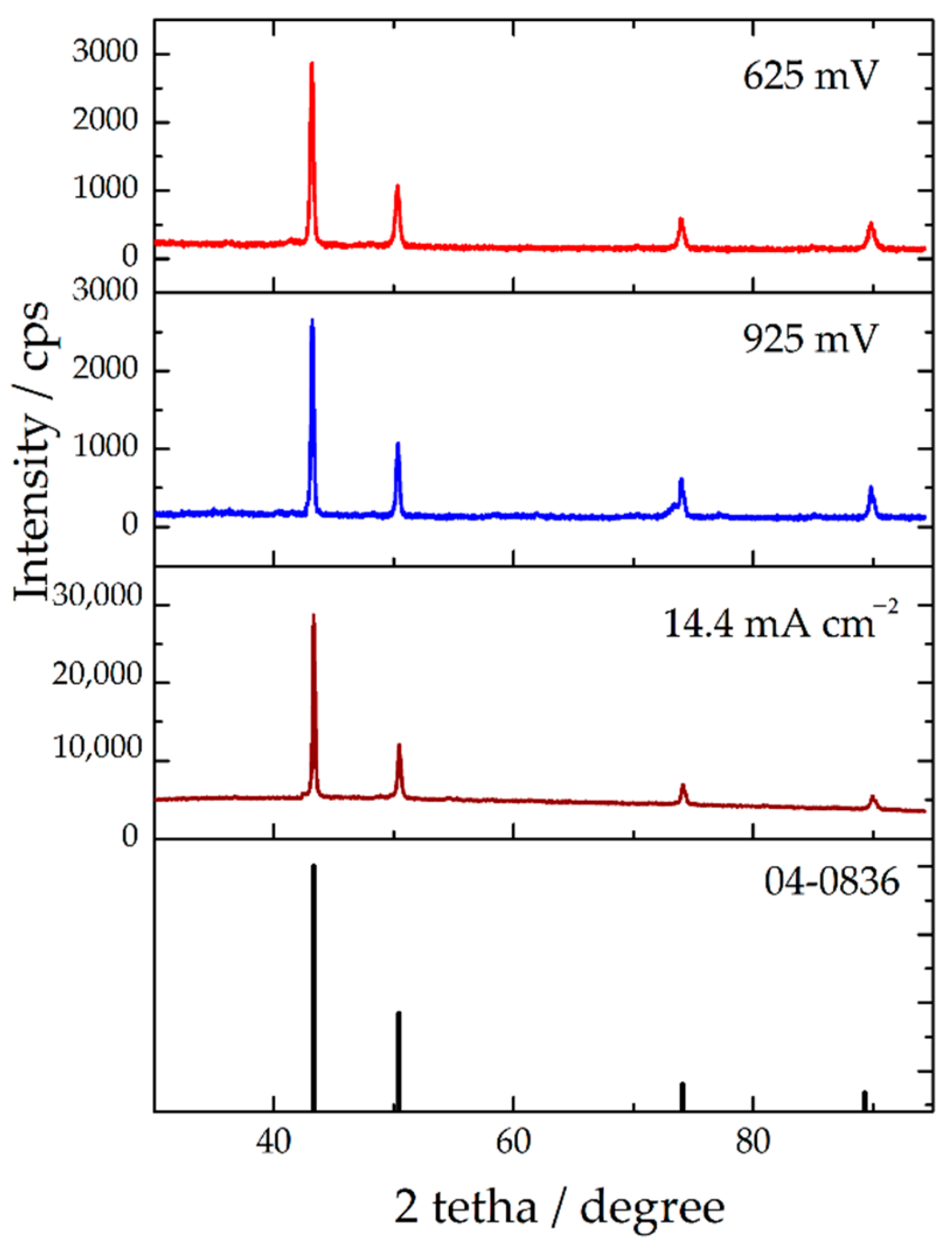

Figure 11. The XRD patterns of $\mathrm{Cu}$ particles obtained from the sulfate electrolyte at overpotentials of 625 and $925 \mathrm{mV}$ and at a current density of $14.4 \mathrm{~mA} \mathrm{~cm}^{-2}$ and $\mathrm{Cu}$ standard (04-0836) ([19] and reprinted from [38] with permission from Elsevier). 
Table 4. Texture calculations for $\mathrm{Cu}$ powders produced potentiostatically at $\eta$ of 625 and $925 \mathrm{mV}$ and galvanostatically at $j$ of $14.4 \mathrm{~mA} \mathrm{~cm}{ }^{-2}\left(625-\eta=625 \mathrm{mV} ; 925-\eta=925 \mathrm{mV} ; 14.4-j=14.4 \mathrm{~mA} \mathrm{~cm}^{-2}\right.$; $\mathrm{s}-\mathrm{Cu}$ standard) ([19] and reprinted from [38] with permission from Elsevier).

\begin{tabular}{|c|c|c|c|c|c|c|c|c|c|c|}
\hline \multirow{2}{*}{$\begin{array}{c}\text { Plane } \\
(h k l)\end{array}$} & \multicolumn{3}{|c|}{$R(\mathrm{in} \%)$} & \multirow{2}{*}{$\begin{array}{c}R_{\mathrm{s}} \\
(\text { in } \%)\end{array}$} & \multicolumn{3}{|c|}{$T C$} & \multicolumn{3}{|c|}{ RTC (in\%) } \\
\hline & $R_{625}$ & $R_{925}$ & $R_{14.4}$ & & $T C_{625}$ & $T C_{925}$ & $T C_{14.4}$ & $R T C_{625}$ & $R T C_{925}$ & $R T C_{14.4}$ \\
\hline (111) & 56.9 & 54.7 & 54.1 & 54.6 & 1.04 & 1.00 & 0.99 & 25.7 & 24.0 & 23.6 \\
\hline$(200)$ & 21.2 & 22.0 & 22.5 & 25.1 & 0.845 & 0.876 & 0.90 & 20.1 & 21.0 & 21.5 \\
\hline$(220)$ & 11.6 & 12.7 & 13.1 & 10.9 & 1.06 & 1.16 & 1.20 & 26.2 & 27.8 & 28.6 \\
\hline$(311)$ & 10.3 & 10.6 & 10.3 & 9.4 & 1.10 & 1.13 & 1.10 & 27.2 & 27.1 & 26.3 \\
\hline
\end{tabular}

\subsection{Inert Metals}

Electrodeposition of metals belonging to the group of the inert metals, such as Ni, Co, $\mathrm{Fe}$ and $\mathrm{Pt}$, occurs together with the reaction of hydrogen evolution at all current densities and cathodic potentials [10]. For that reason, it is not possible to record polarization curves without IR drop compensation $[10,39,40]$.

Nickel

The spongy-like particles were produced by Ni electrodeposition at $j$ of $1265 \mathrm{~mA} \mathrm{~cm}{ }^{-2}$ (Figure 12). This type of the particles with the honeycomb-like structure (Figure 12a) [20] consists of holes obtained by the detachment of hydrogen bubbles surrounded by agglomerates of approximately spherical grains (Figure 12b).

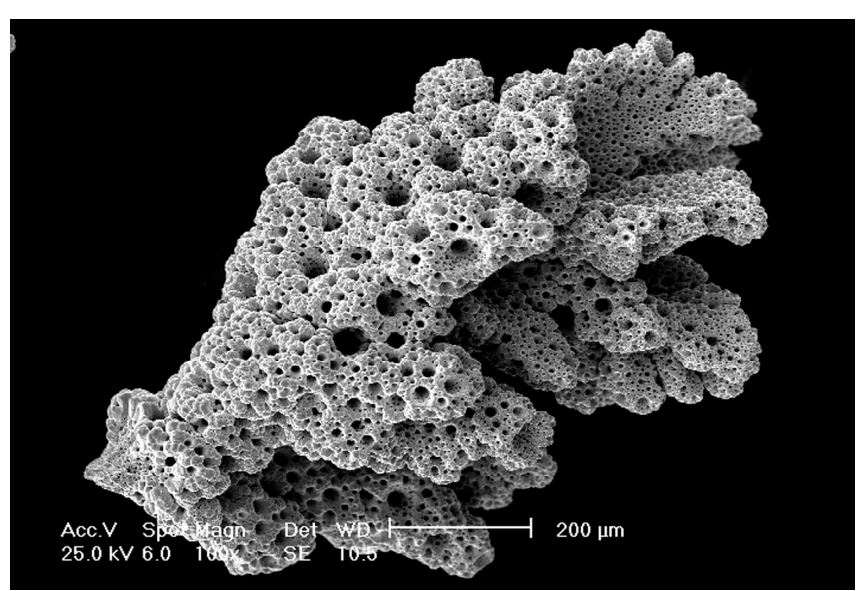

(a)

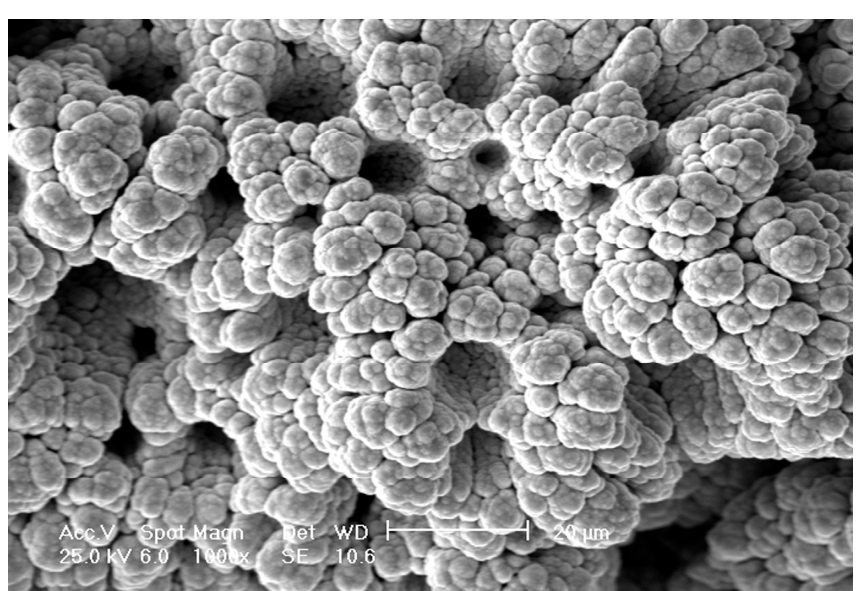

(b)

Figure 12. (a) Morphology of the spongy-like particle obtained by Ni electrodeposition from $1 \mathrm{M} \mathrm{NH}_{4} \mathrm{Cl}+0.7 \mathrm{M} \mathrm{NH} \mathrm{OH}_{4}+$ $0.1 \mathrm{M} \mathrm{NiCl}_{2}$ at $j$ of $1265 \mathrm{~mA} \mathrm{~cm}^{-2}$, and (b) detail of the particle shown under (a) [20].

The XRD pattern for the spongy-like Ni particles together with Ni standard (04-0850) is presented in Figure 13. The diffraction peaks recorded at $2 \theta$ angles of $44.5,51.8,76.4$, and $92.9^{\circ}$ corresponding to (111), (200), (220), and (311) crystal planes confirm the fcc crystal lattice of Ni. The values of the calculated TC $(h k l)$ and $R T C(h k l)$ coefficients (Table 5) clearly indicate the random orientation of Ni crystallites in the spongy-like particles. 


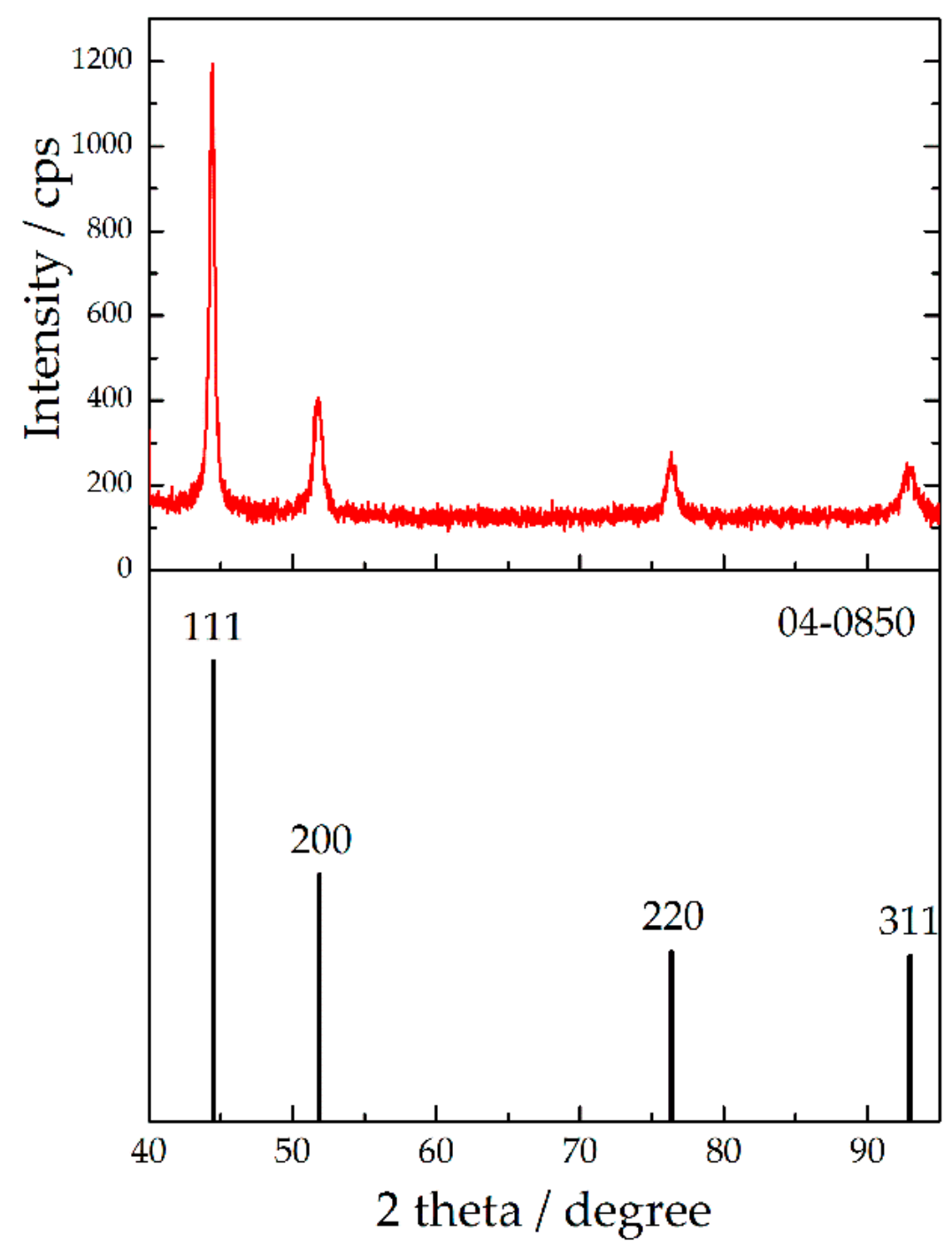

Figure 13. The XRD pattern of Ni particles produced from the chloride solution at $j$ of $1265 \mathrm{~mA} \mathrm{~cm}^{-2}$ and Ni standard (04-0850) [20].

Table 5. The values of $R, T C$, and $R T C$ calculated for Ni particles produced by electrodeposition from the chloride solution at $j$ of $1265 \mathrm{~mA} \mathrm{~cm}^{-2}$ (s-Ni standard) [20].

\begin{tabular}{ccccc}
\hline Plane $(\boldsymbol{h k l )}$ & $\boldsymbol{R}$ (in\%) & $\boldsymbol{R}_{\mathbf{s}}$ (in \%) & $\boldsymbol{T C}$ & $\boldsymbol{R T C}$ (in\%) \\
\hline$(111)$ & 56.9 & 54.6 & 1.04 & 26.1 \\
\hline$(200)$ & 19.6 & 23.0 & 0.85 & 21.3 \\
\hline$(220)$ & 12.2 & 11.5 & 1.06 & 26.5 \\
\hline$(311)$ & 11.3 & 10.9 & 1.04 & 26.1 \\
\hline
\end{tabular}

\subsection{Correlation between Morphology and Crystal Structure of the Powder Particles}

Depending on the exchange current density and overpotential for hydrogen evolution reaction, two types of powder particles are obtained by electrolysis:

(a) The dendrites of various shape-needle-like, 2D fern-like, and the 3D pine-like;

(b) The cauliflower-like and the spongy-like particles.

With the decrease in $j_{0}$ value, the preferred orientation of powder particles changed from the strong (111) obtained for the fern-like dendrites of $\mathrm{Pb}$ and the needle-like dendrites of Ag to the randomly oriented crystallites in all types of the particles with the spherical 
morphology (the 3D dendrites and the cauliflower-like particles of $\mathrm{Cu}$ and the spongy-like Ni particles).

The dendrites are obtained either without a parallel hydrogen evolution as the second reaction $(\mathrm{Pb}$ and $\mathrm{Ag})[18,20,34]$ or with an amount of generated hydrogen that was not enough to achieve any influence on hydrodynamic conditions in the near-electrode layer $(\mathrm{Cu})[19,35]$. The cauliflower-like and the spongy-like particles are obtained under the strong effect of parallel hydrogen evolution reaction [16,41,42].

Although morphological features of the obtained dendrites were very different, all types (the needle-like, fern-like, and the pine-like dendrites of Ag and those of Cu synthesized potentiostatically) followed the electrochemical definition of a dendrite. For the dendrites of $\mathrm{Pb}$ and $\mathrm{Ag}$, the fast growth of the current density after the end of the plateau of the limiting diffusion current density (Figures 2, 3, 5, 7 and 8) is caused by the activation controlled growth of the tips of both the trunk and the branches, which is followed by the strong increase in the real electrode surface area.

The 3D pine-like shape of Ag dendrites produced by the use of the ammonium electrolyte is a typical shape of dendrites obtained by electrolysis from the complex electrolytes of Ag. Similar shapes are also formed by the application of tungstosilicate [43] and citric [44] acids. These compounds form enough strong complexes with $\mathrm{Ag}(\mathrm{I})$ ions to cause a decrease in $j_{0}$ for $\mathrm{Ag}$ and its transfer from the group of the normal metals into the group of the intermediate metals. The 3D pine-like dendrites of $\mathrm{Cu}$ with well-defined corncob-like branches represent the typical shape of $\mathrm{Cu}$ dendrites obtained by electrolysis processes [45-48].

The second subtype of the 3D Cu dendrites is obtained by the galvanostatic regime of electrolysis, and this subtype is constructed from globules (Figure 10g-i). The formation of globular particles, i.e., almost ideal spheres, is primarily a feature of some other methods of powder production, such as the ultrasonic spray pyrolysis [3] and the gas-atomizing process [49]. The spherical particles can be also produced by electrolysis in the presence of additional agents such as a combination of potassium ferrocyanide and 2,2'-dipyridine [50]. Without additives, the globules as a constitutive element of the 3D dendrites can be only obtained galvanostatically under the controlled conditions of electrolysis. They are obtained by the completion of the electrolysis process at the overpotential corresponding to a formation of globules in the potentiostatic mode of electrolysis [51]. In a galvanostatic regime of electrolysis, overpotential decreases with electrolysis time due to an increase in the electrode surface area which then causes a decrease in the real current density. In the potentiostatic mode of $\mathrm{Cu}$ electrodeposition, globules are formed at both the end of the mixed activation-diffusion control and at the beginning of the full diffusion control. The final overpotential corresponding to the formation of the 3D dendrites shown in Figure $10 \mathrm{~g}-\mathrm{i}$ is about $275 \mathrm{mV}$, and this overpotential corresponded to the end of the mixed activation-diffusion control [51].

As already mentioned, vigorous hydrogen evolution is responsible for obtaining the cauliflower-like and spongy-like particles. The intensive hydrogen evolution causes an electrolyte stirring in the near-electrode layer, leading to an increase in the limiting diffusion current density, a decrease in the thickness of the diffusion layer, and, hence, a decrease in the degree of the diffusion control $[10,16]$. There is a critical amount of generated hydrogen causing the change of hydrodynamic conditions in the near-electrode layer, and for $\mathrm{Cu}$, this amount is estimated to correspond to the average current efficiency of hydrogen evolution $\left(\eta_{\mathrm{I}, a v}\left(\mathrm{H}_{2}\right)\right)$ of $10 \%$ [10]. The $\mathrm{Cu}$ particles shown in Figure $10 \mathrm{~d}-\mathrm{f}$ were obtained with $\eta_{\mathrm{I}, \mathrm{av}}\left(\mathrm{H}_{2}\right)$ of $36.6 \%$ [38]. The concept of "effective overpotential" is proposed to explain the obtaining of these particles. According to this concept, when hydrogen evolution is intensive enough to exceed a critical value for a change of hydrodynamic conditions in the near-electrode layer, the electrolysis process occurs at an overpotential that is effectively lower than the specified value, and this overpotential is then called "effective overpotential". The formation of the cauliflower-like particles in the case of $\mathrm{Cu}$ and the spongy-like particles with the same structure in the case of $\mathrm{Ni}$ confirms that they are formed on the lower degree of the diffusion control relative to dendrite formation. In the case of copper, the fast growth 
in the current density after the end of the plateau of the limiting diffusion current density is caused by vigorous hydrogen evolution (Figure 7).

The change of preferred orientation from the strong (111) for the $\mathrm{Pb}$ and $\mathrm{Ag}$ particles to the random orientation in the particles with spherical morphology (the 3D Ag and $\mathrm{Cu}$ dendrites, the cauliflower-like $\mathrm{Cu}$ particles, and the spongy-like Ni particles) can be explained by various rates of growth on various crystal planes [52]. This is related to values of the surface energy of crystal faces, which for fcc crystal lattice follow a trend of $\gamma(111)<\gamma(100)<\gamma(311)<\gamma(110)[53,54]$. The electrodeposition rates on them follow an opposite trend from the $\gamma$ values, i.e., (110) $>(311)>(100)>(111)$. The (110), (311), and (100) belong to the fast-growing planes, and they disappear firstly in process of growth. The (111) plane is denoted by the slow-growing plane, and it survives the growth process. The origin of crystallites oriented in the (111) plane is from growth centers present in the interior of growing particles ("center type"), while those oriented in the other planes originate from centers present at the tips, edges, and corners of the growing particles ("edge" and "corner" types) [21,55]. For the very fast electrochemical processes characterized by the high $j_{0}$ values, the fast-growing planes fast disappear, while the slow-growing (111) plane survives, constructing a stalk and branches of dendrites and consequently causing the (111) preferred orientation in the particles. With the decrease in $j_{0}$ value, a ramification of dendrites followed by an increase in the number of tips, edges, and corners occurs, which increases the contribution of crystallites oriented in the fast-growing planes. The decrease in the $j_{0}$ values also leads to the appearance of the spherical morphology in the particles, causing a distribution of crystallites in them close to that for the corresponding standard already established for randomly distributed spherical grains.

\section{Formation of Powders by Molten Salt Electrolysis}

The very thin needle-like dendrites often grouped in the flower-like aggregates were produced by electrolysis from magnesium nitrate hexahydrate melt (Figure 14a). There is no difference in the morphology of needles obtained by the application of potentiostatic and galvanostatic regimes of electrolysis $[56,57]$. Unlike electrolysis from the aqueous electrolytes, molten salt electrolysis offers a possibility of direct formation of $\mathrm{MgO}$ next to $\mathrm{Mg}(\mathrm{OH})_{2}$ (Figure 14b). The general theory of disperse deposit formation applied to explain the formation of dendrites from aqueous electrolytes is also valid for dendrite formation by molten salt electrolysis [22].

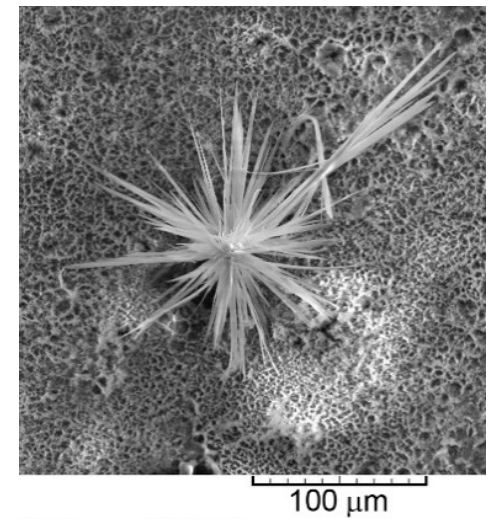

(a)

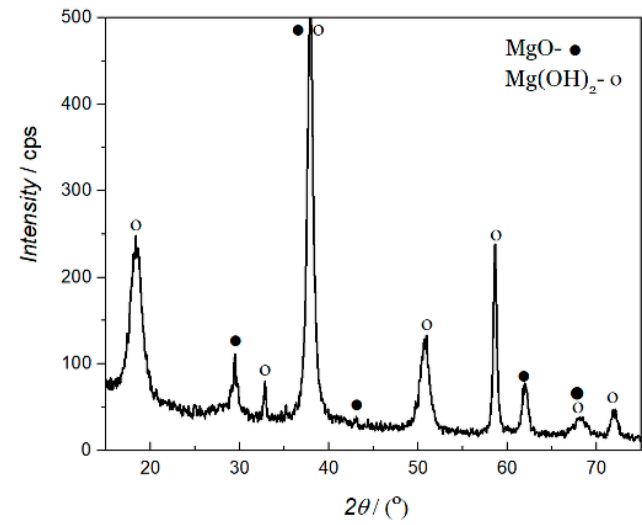

(b)

Figure 14. (a) The flower-like aggregate built from very thin needle-like $\mathrm{MgO} / \mathrm{Mg}(\mathrm{OH})_{2}$ dendrites obtained by electrolysis of magnesium nitrate melt at a potential of $-200 \mathrm{mV}$; (b) the XRD pattern of the particles shown in (a) (reprinted from [56] with permission from Elsevier). 


\section{Formation of Metal Powders by Electrolysis in Deep Eutectic Solvents (DESs)}

In the last decade, deep eutectic solvents (DESs), as a unique class of multicomponent solvent systems formed through hydrogen bond interactions, began to be used for the synthesis of metal powders such as $\mathrm{Pb}[13,58-60]$, Sn [61,62], and Sb [63].

All electrodeposition parameters affecting the shape of $\mathrm{Pb}$ particles during electrolysis from aqueous electrolytes also affect the particle shape obtained from this electrolyte type. Depending on a concentration of $\mathrm{PbO}$ (in choline chloride $(\mathrm{ChCl})$-urea $\mathrm{DES})$, various forms of $\mathrm{Pb}$ powders, such as corals, rods, wires, needles, ferns, and dendritic forms, are obtained, with an increasing tendency of a change of morphology of the particles from coral-like to the $2 \mathrm{D}$ and the $3 \mathrm{D}$ dendrites with the increase in $\mathrm{PbO}$ concentration [58]. Simultaneously, with the increase in $\mathrm{PbO}$ concentration, the preferred orientation of the powders changes from those with crystallites predominantly oriented in the (111) plane to the strong (200) preferred orientation. Sub-micrometer lead wires of various lengths and diameters with crystallites predominantly oriented in the (200) plane were obtained at the various temperatures $[13,59]$. Coral-like particles of varied size and porosity, mainly composed of many overlapped sub-micrometer lead flakes, were obtained by use of various concentrations of galena (PbS) instead of $\mathrm{PbO}$ in the same ChCl-urea DES [60]. The $\mathrm{Pb}$ crystallites in them were predominantly oriented in (111) plane. All mechanisms explaining the formation of $\mathrm{Pb}$ powder particles from the aqueous solutions are also valid for the formation of $\mathrm{Pb}$ powders from this electrolyte type.

Tin (Sn) powder particles with pyramid chain and dendritic structures were dominantly obtained by electrolysis in choline chloride-ethylene glycol deep eutectic solvent (ChCl-EG DES) [61,62]. The morphology of the particles changed from irregular particles to both long straight pyramid chains and 3D dendrites with increasing current density. Aside from the 3D dendrites, the mixture of the needle-like and the 2D dendrites was also formed at the high current density. Simultaneously, the calculated $T C(h k l)$ coefficients showed that this change of the particle morphology was accompanied by the change of the preferred orientation of the particles from (200) to (101) [61]. With an increase in the concentration of $\mathrm{Sn}(\mathrm{II})$ ions, the morphology of the powders changed from the needle-like and the 3D dendrites with well-defined stalk and branches to the particles with pyramid chain structure, the needle-like and the 3D dendrites, and those like coarse pyramids. At the high Sn(II) concentration, the strong (200) preferred orientation is observed, whereas at the low Sn(II) concentration, Sn crystallites were dominantly oriented in the (211) plane [61]. Temperature also had a strong effect on the shape of Sn powder particles electrolytically obtained in $\mathrm{ChCl-EG} \mathrm{DES.} \mathrm{The} \mathrm{change} \mathrm{of} \mathrm{particle} \mathrm{morphology} \mathrm{from} \mathrm{dendrites} \mathrm{to} \mathrm{tower} \mathrm{cone-shaped}$ and pagoda-shaped particles was observed with the increasing reaction temperature [62].

Antimony (Sb) powders consisting of particles of various shapes were obtained by electrolysis in ChCl-EG DES [63]. Depending on the current density and the temperature applied, various forms of the powder particles such as pine cone, wheat grain, badminton, dendritic, and cluster-like were synthesized. In all types of particles, the Sb crystallites were dominantly oriented in the (012) plane.

\section{Crystal Growth and Crystal Structure of Electrodeposited FCC Metals}

As already mentioned, according to the exchange current density, the melting point, and overpotential for hydrogen discharge, metals can be classified into three groups. Further, based on the literature data for the stacking fault energy (SFE) values, it is possible to expand this classification for fcc metals with low, medium, and high SFEs. SFE represents the energy that is associated with the interruption of the normal stacking sequence of a crystal plane, which has a notable influence on the mobility of defects, defect clusters, and dislocations and thus influences the defect evolution and crystal growth. $\mathrm{Ag}$ and $\mathrm{Pb}$ have low stacking fault energies, about 16 [64] and $25 \mathrm{~mJ} \mathrm{~m}^{-2}$ [65], respectively. For $\mathrm{Cu}$ and $\mathrm{Ni}$, different values of SFE can be found in the literature depending on the applied measurement methods. The value of SFE for $\mathrm{Cu}$ ranges from 45 [66] to $85 \mathrm{~mJ} \mathrm{~m}^{-2}$ [65], 
which classifies it as a medium metal. Finally, Ni has a very high SFE that is more than $300 \mathrm{~mJ} \mathrm{~m}^{-2}$ [65].

The shape of an electrodeposited crystal is usually determined by the relative rates of the advance of close-packed faces. Close-packed faces show a relatively slow growth since the only places where atoms can be added are kink sites, while high index faces show a more rapid growth. The total growth rate is determined by the growth of the close-packed faces because the rapid disappearance of the high index faces is a result of their high growth rate. At exceptionally low growth rates when the solution and the crystal are nearly in equilibrium, the shape of faces will be determined by the requirement that the total surface energy of crystals is minimized [67].

$\mathrm{As} \mathrm{Ag}$ and $\mathrm{Pb}$ have low stacking fault energy, they are subject to profuse twinning and stacking fault formation. The $2 \mathrm{D}$ and $3 \mathrm{D}$ dendrites of $\mathrm{Ag}[18,34,64,68]$ and $\mathrm{Pb}[26,29,31]$ are twin crystals.

The 2D dendrites are of fern-like shape because they grow and branch in one plane (Figure 3 for $\mathrm{Pb}$ and Figure $5 \mathrm{c}, \mathrm{d}$ for $\mathrm{Ag}$ ). Branching in one plane only is directly related to the occurrence of growth twins, and at least one twinning boundary is parallel to the plane of the dendrite $[34,69]$. Two or more twin planes guarantee the presence of at least one reentrant edge that is a result of the emergence of a twin plane on a crystal surface, which is a repeatable growth defect in faceted crystals. The twin grooves in nuclei are sites of lower energy for further nucleation and growth than the faces $[34,70]$. The twinning plane in fcc crystal is (111), with stalk and all branches being parallel to the $<211>$ direction growth. Dendrites also grow in thickness, using the layer growth mechanism while the faces appear on the main face of a dendrite. The growth in $<211>$ and $<111>$ directions causes the appearance of 3D dendrites (pine-like dendrites) (Figure 8) [34].

Although $\mathrm{Cu}$ has slightly higher stacking fault energy (medium), its growth is similar to 3D dendrites (pine-like) of Ag electrodeposited from the ammonium electrolyte [38,41]. Dendrites also grow by layer growth mechanism [34]. The dendrites likely branch in the $<111>$ direction, so the main stem and primary branches make an angle of nearly $90^{\circ}$ (Figure 10a,b). In this way, they have a 3D appearance.

Relative to $\mathrm{Pb}, \mathrm{Ag}$, and $\mathrm{Cu}, \mathrm{Ni}$ as metal from the VIIIB group has smaller atomic volumes and higher effective electron numbers, $Z$, which results in a smaller critical dimension for nucleation. Ni possesses vast binding energy and thus favors the aggregation of atoms into small 3D clusters. The diffusion of electrodeposited atoms along the surface is inhibited by the high cohesive energy of this metal, which results in the nucleation, growth, and coalescence of many 3D grains during deposition [71]. Moreover, due to the high stacking fault energy, crystals of Ni are not inclined to twinning (Figure 12).

\section{Conclusions}

Correlation between morphology and crystal structure of metal powders produced by the constant regimes of electrolysis was presented at the semiquantitative level. Morphology of the powder particles was strongly affected by parameters such as the exchange current density (the rate of electrochemical process) and overpotential for hydrogen evolution reaction. It was shown:

- The needle-like and the 2D fern-like dendrites were obtained by electrolysis of metals characterized by the high $j_{0}$ values (silver and lead). The powders composed of these particles possessed either the strong (111) (the needle-like $\mathrm{Ag}$ and the 2D fern-like $\mathrm{Pb}$ dendrites) or the (111) (the 2D fern-like Ag dendrites) preferred orientation.

- The 3D pine-like dendrites, including those built from globules, were produced by electrolysis of metals characterized by medium $j_{0}$ values (Ag electrodeposited from the ammonium solution and $\mathrm{Cu}$ ). The 3D pine-like dendrites were built from approximately spherical grains. The powders composed of these particles possessed a random orientation. 
- The intensive hydrogen evolution as the parallel reaction strongly affected the form of the powder particles. The cauliflower-like $(\mathrm{Cu})$ and the spongy-like $(\mathrm{Ni})$ particles were obtained under vigorous hydrogen evolution. Both types of particles were built from approximately spherical grains. The powders composed of these particles showed a random orientation.

- $\quad$ Formation of metal powders by electrolysis from molten salt $(\mathrm{Mg})$ and electrolysis in deep eutectic solvents $(\mathrm{Pb}, \mathrm{Sn}$, and $\mathrm{Sb})$ was also presented. Special attention was given to the analysis of the morphology and crystal structure of powders obtained by these types of electrolysis.

Author Contributions: Conceptualization, N.D.N.; methodology, N.D.N. and V.M.M.; validation, N.D.N. and V.M.M.; investigation, N.D.N., L.A. and V.M.M.; writing-original draft preparation, N.D.N.; writing-review and editing, N.D.N., L.A. and V.M.M.; visualization, N.D.N.; supervision, N.D.N. All authors have read and agreed to the published version of the manuscript.

Funding: This research was funded by the Ministry of Education, Science and Technological Development of the Republic of Serbia, grant numbers 451-03-9/2021-14/200026, and 451-03-9/2021$14 / 200017$.

Institutional Review Board Statement: Not applicable.

Informed Consent Statement: Not applicable.

Data Availability Statement: The data presented in this study are available on request from the corresponding author or co-authors. The data are not publicly available.

Conflicts of Interest: The authors declare no conflict of interest.

\section{Appendix A}

The "Texture Coefficient" TC $(h k l)$ and the "Relative Texture Coefficient" $R T C(h k l)$ were determined by analysis of the XRD data. The ratio of reflection intensity $(h k l)$ to the sum of all intensities of the recorded reflections, $R(h k l)$, (in\%) is given by Equation (A1) [18,19]:

$$
R(h k l)=\left(I(h k l) / \sum_{i}^{4} I\left(h_{i} k_{i} l_{i}\right)\right) \times 100
$$

where $I(h k l)$ is a reflection intensity $(h k l)$ plane, in cps, and $\sum_{i}^{4} I(h k l)$ is the sum of all intensities of the recorded reflections, in cps, for the powder being considered.

The "Texture Coefficient", $T C(h k l)$, for every $(h k l)$ reflection is defined by Equation (A2):

$$
T C(h k l)=\frac{R(h k l)}{R_{s}(h k l)}
$$

where $R_{\mathrm{S}}(h k l)$ is defined in the same way as given by Equation (A2) but is related to the standard for metal under consideration. This coefficient gives accurate quantitative information about the absolute reflection intensity.

Finally, the "Relative Texture Coefficient", RTC $(h k l)$, is defined by Equation (A3):

$$
R T C(h k l)=\left(T C(h k l) / \sum_{i}^{4} T C\left(h_{i} k_{i} l_{i}\right)\right) \times 100
$$

The $R T C(h k l)$ coefficient defines the reflection intensity $(h k l)$ relative to the standard (included in the TC values). 


\section{References}

1. Popov, K.I.; Pavlović, M.G. Metal Powder Production by Electrolysis. In Electrochemistry Encyclopedia; The Electrochemical Society: Pennington, NJ, USA, 2005; Available online: https:// knowledge.electrochem.org/encycl/art-p04-metalpowder.htm. (accessed on 17 March 2021).

2. Making Metal Powder. Available online: https://www.mpif.org/IntrotoPM/MakingMetalPowder.aspx. (accessed on 17 March 2021).

3. Stopić, S.; Dvorak, P.; Friedrich, B. Synthesis of Spherical Nanosized Copper Powder by Ultrasonic Spray Pyrolysis. World Metall. 2005, 58, 195-201.

4. Meshram, P.; Sinha, M.K.; Sahu, S.K.; Khan, P.; Pandey, B.D.; Mankhand, T.R. Solvothermal Synthesis of High Value Copper Powder from Copper Bleed Solution of an Indian Copper Smelter. Powder Technol. 2013, 233, 335-340. [CrossRef]

5. Jhajharia, R.; Jain, D.; Sengar, A.; Goyal, A.; Soni, P.R. Synthesis of Copper Powder by Mechanically Activated Cementation. Powder Technol. 2016, 301, 10-15. [CrossRef]

6. Rosenband, V.; Gany, A. Preparation of Nickel and Copper Submicrometer Particles by Pyrolysis of their Formats. J. Mater. Process. Technol. 2004, 153, 1058-1061. [CrossRef]

7. Djokić, S.S. Production of Metallic Powders from Aqueous Solutions without an External Current Source. In Electrochemical Production of Metal Powders, Series: Modern Aspects of Electrochemistry; Djokić, S.S., Ed.; Springer: New York, NY, USA, 2012; Volume 54, pp. 369-398.

8. Antony, L.V.M.; Reddy, R.G. Processes for Production of High-Purity Metal Powders. JOM 2003, 55, 14-18. [CrossRef]

9. Chaubey, A.K.; Scudino, S.; Khoshkhoo, M.S.; Prashanth, K.G.; Mukhopadhyay, N.K.; Mishra, B.K.; Eckert, J. Synthesis and Characterization of Nanocrystalline Mg-7.4\%Al Powders Produced by Mechanical Alloying. Metals 2013, 3, 58-68. [CrossRef]

10. Popov, K.I.; Djokić, S.S.; Nikolić, N.D.; Jović, V.D. Morphology of Electrochemically and Chemically Deposited Metals; Springer: New York, NY, USA, 2016; pp. 1-368.

11. Amiri, M.; Nouhi, S.; Azizian-Kalandaragh, Y. Facile Synthesis of Silver Nanostructures by Using Various Deposition Potential and Time: A Nonenzymatic Sensors for Hydrogen Peroxide. Mater. Chem. Phys. 2015, 155, 129-135. [CrossRef]

12. Calusaru, A. Electrodeposition of Metal Powders; Elsevier: New York, NY, USA, 1979; pp. 1-544.

13. Ru, J.; Hua, Y.; Xu, C.; Li, J.; Li, Y.; Wang, D.; Gong, K.; Zhou, Z. Preparation of Sub-micrometer Lead Wires from PbO by Electrodeposition in Choline Chloride-urea Deep Eutectic Solvent. Adv. Powder Technol. 2015, 26, 91-97. [CrossRef]

14. Winand, R. Electrodeposition of Metals and Alloys-New Results and Perspectives. Electrochim. Acta 1994, 39, 1091-1105. [CrossRef]

15. Nikolić, N.D. Influence of the Exchange Current Density and Overpotential for Hydrogen Evolution Reaction on the Shape of Electrolytically Produced Disperse Forms. J. Electrochem. Sci. Eng. 2020, 10, 111-126. [CrossRef]

16. Nikolić, N.D.; Popov, K.I.; Pavlović, L.J.; Pavlović, M.G. The Effect of Hydrogen Codeposition on the Morphology of Copper Electrodeposits. I. The Concept of Effective Overpotential. J. Electroanal. Chem. 2006, 588, 88-98. [CrossRef]

17. Berube, L.P.; Esperance, G.L. A Quantitative Method of Determining of the Degree of Texture of Zinc Electrodeposits. J. Electrochem. Soc. 1989, 136, 2314-2315. [CrossRef]

18. Avramović, L.; Pavlović, M.M.; Maksimović, V.M.; Vuković, M.; Stevanović, J.S.; Bugarin, M.; Nikolić, N.D. Comparative Morphological and Crystallographic Analysis of Electrochemically- and Chemically-Produced Silver Powder Particles. Metals 2017, 7, 160. [CrossRef]

19. Avramović, L.; Maksimović, V.M.; Baščarević, Z.; Ignjatović, N.; Bugarin, M.; Marković, R.; Nikolić, N.D. Influence of the Shape of Copper Powder Particles on the Crystal Structure and Some Decisive Characteristics of the Metal Powders. Metals 2019, 9, 56. [CrossRef]

20. Nikolić, N.D.; Maksimović, V.M.; Branković, G.; Živković, P.M.; Pavlović, M.G. Correlation between Crystal Orientation and Morphology of Electrolytically Produced Powder Particles: Analysis of the Limiting Cases. Mater. Prot. 2018, 59, 256-264. [CrossRef]

21. Wranglen, G. Dendrites and Growth Layers in the Electrocrystallization of Metals. Electrochim. Acta 1960, 2, 130-146. [CrossRef]

22. Popov, K.I.; Nikolić, N.D. General Theory of Disperse Metal Electrodeposits Formation. In Electrochemical Production of Metal Powders, Series: Modern Aspects of Electrochemistry; Djokić, S.S., Ed.; Springer: New York, NY, USA, 2012; Volume 54, pp. 1-62.

23. Diggle, J.W.; Despic, A.R.; Bockris, J.O.'M. The Mechanism of the Dendritic Electrocrystallization of Zinc. J. Electrochem. Soc. 1969, 116, 1503-1514. [CrossRef]

24. Nikolić, N.D.; Živković, P.M.; Branković, G.; Pavlović, M.G. Estimation of the Exchange Current Density and Comparative Analysis of Morphology of Electrochemically Produced Lead and Zinc Deposits. J. Serb. Chem. Soc. 2017, 82, 539-550. [CrossRef]

25. Fetter, K. Electrochemical Kinetics; Khimiya: Moscow, Russia, 1967. (In Russian)

26. Nikolić, N.D.; Branković, G.; Lačnjevac, U. Formation of Two-dimensional (2D) Lead Dendrites by Application of Different Regimes of Electrolysis. J. Solid State Electrochem. 2012, 16, 2121-2126. [CrossRef]

27. Nikolić, N.D.; Vaštag, D.D.; Živković, P.M.; Jokić, B.; Branković, G. Influence of the Complex Formation on the Morphology of Lead Powder Particles Produced by the Electrodeposition Processes. Adv. Powder Technol. 2013, 24, 674-682. [CrossRef]

28. Nikolić, N.D.; Popov, K.I.; Živković, P.M.; Branković, G. A New Insight into the Mechanism of Lead Electrodeposition: Ohmicdiffusion Control of the Electrodeposition Process. J. Electroanal. Chem. 2013, 691, 66-76. [CrossRef] 
29. Nikolić, N.D.; Popov, K.I.; Ivanović, E.R.; Branković, G.; Stevanović, S.I.; Živković, P.M. The Potentiostatic Current Transients and the Role of Local Diffusion Fields in Formation of the 2D Lead Dendrites from the Concentrated Electrolyte. J. Electroanal. Chem. 2015, 739, 137-148. [CrossRef]

30. Wong, S.M.; Abrantes, L.M. Lead Electrodeposition from Very Alkaline Media. Electrochim. Acta 2005, 51, 619-626. [CrossRef]

31. Nikolić, N.D.; Vaštag, D.D.; Maksimović, V.M.; Branković, G. Morphological and Crystallographic Characteristics of Lead Powder Obtained by Electrodeposition from an Environmentally Friendly Electrolyte. Trans. Nonferrous Met. Soc. China 2014, $24,884-892$. [CrossRef]

32. Ni, Y.; Zhang, Y.; Hong, J. Hierarchical Pb Microstructures: A Facile Electrochemical Synthesis, Shape Evolution and Influencing Factors. CrystEngComm 2011, 13, 934-940. [CrossRef]

33. Sivasubramanian, R.; Sangaranarayanan, M.V. Electrodeposition of Silver Nanostructures: From Polygons to Dendrites. CrystEngComm 2013, 15, 2052-2056. [CrossRef]

34. Avramović, L.; Ivanović, E.R.; Maksimović, V.M.; Pavlović, M.M.; Vuković, M.; Stevanović, J.S.; Nikolić, N.D. Correlation between Crystal Structure and Morphology of Potentiostatically Electrodeposited Silver Dendritic Nanostructures. Trans. Nonferrous Met. Soc. China 2018, 28, 1903-1912. [CrossRef]

35. Nikolić, N.D.; Popov, K.I. A New Approach to the Understanding of the Mechanism of Lead Electrodeposition. In Electrodeposition and Surface Finishing; Series: Modern Aspects of Electrochemistry; Djokić, S.S., Ed.; Springer: New York, NY, USA, 2014; Volume 57, pp. 85-132.

36. Popov, K.I.; Krstajić, N.V.; Popov, S.R. Fundamental Aspects of Plating Technology II: Morphological Aspects of Metal Electrodeposition from Complex Salt Solutions. Surf. Technol. 1983, 20, 203-208. [CrossRef]

37. Popov, K.I.; Grgur, B.N.; Stojilković, E.R.; Pavlović, M.G.; Nikolić, N.D. The Effect of Deposition Process Exchange Current Density on the Thin Metal Film Formation on Inert Substrate. J. Serb. Chem. Soc. 1997, 62, 433-442.

38. Nikolić, N.D.; Avramović, L.; Ivanović, E.R.; Maksimović, V.M.; Baščarević, Z.; Ignjatović, N. Comparative Morphological and Crystallographic Analysis of Copper Powders Obtained under Different Electrolysis Conditions. Trans. Nonferrous Met. Soc. China 2019, 29, 1275-1284. [CrossRef]

39. Jović, V.D.; Jović, B.M.; Pavlović, M.G. Electrodeposition of Ni, Co and Ni-Co Alloy Powders. Electrochim. Acta 2006, 51, 5468-5477. [CrossRef]

40. Jović, V.D.; Nikolić, N.D.; Lačnjevac, U.Č.; Jović, B.M.; Popov, K.I. Morphology of Different Electrodeposited Pure Metal Powders. In Electrochemical Production of Metal Powders; Series: Modern Aspects of Electrochemistry; Djokić, S.S., Ed.; Springer: New York, NY, USA, 2012; Volume 54, pp. 63-123.

41. Nikolić, N.D.; Pavlović, L.J.; Pavlović, M.G.; Popov, K.I. Morphologies of Electrochemically Formed Copper Powder Particles and their Dependence on the Quantity of Evolved Hydrogen. Powder Technol. 2008, 185, 195-201. [CrossRef]

42. Nikolić, N.D.; Branković, G.; Pavlović, M.G. Correlate Between Morphology of Powder Particles Obtained by the Different Regimes of Electrolysis and the Quantity of Evolved Hydrogen. Powder Technol. 2012, 221, 271-277. [CrossRef]

43. Han, J.; Liu, J. Electrodeposition of Crystalline Dendritic Silver in 12-Tungstosilicate Acid System. J. Nanoeng. Nanomanuf. 2012, 2, 171-174. [CrossRef]

44. Mandke, M.V.; Han, S.-H.; Pathan, H.M. Growth of Silver Dendritic Nanostructures via Electrochemical Route. CrystEngComm 2012, 14, 86-89. [CrossRef]

45. Orhan, G.; Hapci, G. Effect of Electrolysis Parameters on the Morphologies of Copper Powder Obtained in a Rotating Cylinder Electrode Cell. Powder Technol. 2010, 201, 57-63. [CrossRef]

46. Ostanina, T.N.; Rudoi, V.M.; Patrushev, A.V.; Darintseva, A.B.; Farlenkov, A.S. Modelling the Dynamic Growth of Copper and Zinc Dendritic Deposits under the Galvanostatic Electrolysis Conditions. J. Electroanal. Chem. 2015, 750, 9-18. [CrossRef]

47. Nikitin, V.S.; Ostanina, T.N.; Rudoi, V.M.; Kuloshvili, T.S.; Darintseva, A.B. Features of Hydrogen Evolution during Electrodeposition of Loose Deposits of Copper, Nickel and Zinc. J. Electroanal. Chem. 2020, 870, 114230. [CrossRef]

48. Nekouei, R.K.; Rashchi, F.; Ravanbakhsh, A. Copper Nanopowder Synthesis by Electrolysis Method in Nitrate and Sulfate Solutions. Powder Technol. 2013, 250, 91-96. [CrossRef]

49. Copper Powder. Available online: http://www.cnpcpowder.com/products/copper/ (accessed on 17 March 2021).

50. Lou, W.; Cai, W.; Li, P.; Su, J.; Zheng, S.; Zhang, Y.; Jin, W. Additives-assisted Electrodeposition of Fine Spherical Copper Powder from Sulfuric Acid Solution. Powder Technol. 2018, 326, 84-88. [CrossRef]

51. Nikolić, N.D.; Živković, P.M.; Pavlović, M.G.; Baščarević, Z. Overpotential Controls a Morphology of Electrolytically Produced Copper Dendritic Forms. J. Serb. Chem. Soc. 2019, 84, 1209-1220. [CrossRef]

52. Bockris, J.O.'M.; Reddy, A.K.N.; Gamboa-Aldeco, M.E. Modern Electrochemistry 2A, Fundamentals of Electrodics; Kluwer Academic/Plenum Publishers: New York, NY, USA; Springer: Boston, MA, USA, 2000; p. 1333.

53. Zhang, J.M.; Ma, F.; Xu, K.W. Calculation of the Surface Energy of FCC Metals with Modified Embedded-atom Method. Appl. Surf. Sci. 2004, 229, 34-42. [CrossRef]

54. Wang, S.G.; Tian, E.K.; Lung, C.W. Surface Energy of Arbitrary Crystal Plane of bcc and fcc Metals. J. Phys. Chem. Solids 2000, 61, 1295-1300. [CrossRef]

55. Nikolić, N.D.; Maksimović, V.M.; Branković, G. Morphological and Crystallographic Characteristics of Electrodeposited Lead from the Concentrated Electrolyte. RSC Adv. 2013, 3, 7466-7471. [CrossRef] 
56. Cvetković, V.S.; Vukićević, N.M.; Nikolić, N.D.; Branković, G.; Barudžija, T.S.; Jovićević, J.N. Formation of Needle-like and Honeycomb-like Magnesium Oxide/Hydroxide Structures by Electrodeposition from Magnesium Nitrate Melts. Electrochim. Acta 2018, 268, 494-502. [CrossRef]

57. Cvetković, V.S.; Vukićević, N.M.; Nikolić, N.D.; Baščarević, Z.; Barudžija, T.S.; Jovićević, J.N. A Possible Mechanism of Formation of Flower-like $\mathrm{MgO} / \mathrm{Mg}(\mathrm{OH})_{2}$ Structures by Galvanostatic Molten Salt Electrolysis: The Concept of Local Diffusion Fields. J. Electroanal. Chem. 2019, 842, 168-175. [CrossRef]

58. Ru, J.; Hua, Y.; Xu, C.; Li, J.; Li, Y.; Wang, D.; Qi, C.; Jie, Y. Morphology-controlled Preparation of Lead Powders by Electrodeposition from Different PbO-containing Choline Chloride-urea Deep Eutectic Solvent. Appl. Surf. Sci. 2015, 335, 153-159. [CrossRef]

59. Ru, J.; Hua, Y.; Xu, C.; Li, J.; Li, Y.; Wang, D.; Qi, C.; Gong, K. Electrochemistry of Pb(II)/Pb during Preparation of Lead Wires from $\mathrm{PbO}$ in Choline Chloride-Urea Deep Eutectic Solvent. Russ. J. Electrochem. 2015, 51, 773-781. [CrossRef]

60. Ru, J.; Bu, J.; Wang, Z.; Hua, Y.; Wang, D. Eco-friendly and Facile Electrochemical Synthesis of Sub-micrometer Lead Powders in Deep Eutectic Solvents Using Galena as a Raw Material. J. Appl. Electrochem. 2019, 49, 369-377. [CrossRef]

61. Wang, Z.; Ru, J.; Hua, Y.; Bu, J.; Geng, X.; Zhang, W. Electrodeposition of Sn Powders with Pyramid Chain and Dendrite Structures in Deep Eutectic Solvent: Roles of Current Density and $\mathrm{SnCl}_{2}$ Concentration. J. Solid State Electrochem. 2021, 25, 1111-1120. [CrossRef]

62. Wang, Z.; Ru, J.; Hua, Y.; Wang, D.; Bu, J. Morphology-Controlled Preparation of Sn Powders by Electrodeposition in Deep Eutectic Solvent as Anodes for Lithium Ion Batteries. J. Electrochem. Soc. 2020, 167, 082504. [CrossRef]

63. Bu, J.; Ru, J.; Wang, Z.; Hua, Y.; Xu, C.; Zhang, Y.; Wang, Y. Controllable Preparation of Antimony Powders by Electrodeposition in Choline Chloride-ethylene Glycol. Adv. Powder Technol. 2019, 30, 2859-2867. [CrossRef]

64. Radmilovic, V.V.; Kacher, J.; Ivanovic, E.R.; Minor, A.M.; Radmilovic, V.R. Multiple Twinning and Stacking Faults in Silver Dendrites. Cryst. Growth Des. 2016, 16, 467-474. [CrossRef]

65. Smallman, R.; Dillamore, I.; Dobson, P. The Measurement of Stacking Fault Energy. J. Phys. Colloq. 1966, 27, C3-86-C3-93. [CrossRef]

66. Liu, F.; Yuan, H.; Yin, J.; Wang, J.T. Influence of Stacking Fault Energy and Temperature on Microstructures and Mechanical Properties of fcc Pure Metals Processed by Equal-channel Angular Pressing. Mat. Sci. Eng. A Struct. 2016, 662, 578-587. [CrossRef]

67. Cabrera, N.; Vermilyea, D.A. The Growth of Crystals from Solution. In Growth and Perfection of Crystals; Doremus, R.H., Roberts, B.W., Turnbull, D., Eds.; John Wiley \& Sons: New York, NY, USA; Chapman \& Hall: London, UK, 1958; pp. $393-410$.

68. Ivanović, E.R.; Nikolić, N.D.; Radmilović, V.R. Randomly Oriented Twin Domains in Electrodeposited Silver Dendrites. J. Serb. Chem. Soc. 2015, 80, 107-113. [CrossRef]

69. Smit, J.; Ogburn, F.; Bechtoldt, C.J. Multiple Twin Structures in Electrodeposited Silver Dendrites. J. Electrochem. Soc. 1968, 115, 371-374. [CrossRef]

70. Hamilton, D.R.; Seidensticker, R.G.J. Propagation Mechanism of Germanium Dendrites. Appl. Phys. 1960, 31, 1165-1168. [CrossRef]

71. Tian, M.L.; Wang, J.G.; Kurtz, J.; Mallouk, T.E.; Chan, M.H.W. Electrochemical Growth of Single-Crystal Metal Nanowires via a Two-Dimensional Nucleation and Growth Mechanism. Nano Lett. 2003, 3, 919-923. [CrossRef] 